\title{
The role of lipids in autophagy and its implication in neurodegeneration
}

\author{
Sergio Hernandez-Diaz ${ }^{1,2}$ and Sandra-Fausia Soukup ${ }^{1,2, *}$ \\ 1 Université de Bordeaux, Institut des Maladies Neurodégénératives, UMR 5293, 33000, Bordeaux, France. \\ ${ }^{2}$ CNRS, Institut des Maladies Neurodégénératives, UMR 5293, 33000, Bordeaux, France. \\ * Corresponding Author: \\ Sandra-Fausia Soukup, University of Bordeaux, Neurodegenerative Diseases Institute, UMR 5293, F-33000 Bordeaux, France; E-mail: \\ Sandra.soukup@u-bordeaux.fr
}

ABSTRACT Neurodegenerative diseases are, at present, major socio-economic burdens without effective treatments and their increasing prevalence means that these diseases will be a challenge for future generations. Neurodegenerative diseases may differ in etiology and pathology but are often caused by the accumulation of dysfunctional and aggregation-prone proteins. Autophagy, a conserved cellular mechanism, deals with cellular stress and waste product build-up and has been shown to reduce the accumulation of dysfunctional proteins in animal models of neurodegenerative diseases. Historically, progress in understanding the precise function of lipids has traditionally been far behind other biological molecules (like proteins) but emerging works demonstrate the importance of lipids in the autophagy pathway and how the disturbance of lipid metabolism is connected to neurodegeneration. Here we review how altered autophagy and the disturbance of lipid metabolism, particularly of phosphoinositols and sphingolipids, feature in neurodegenerative diseases and address work from the field that suggests that these potentially offer an opportunity of therapeutic intervention. doi: $10.15698 /$ cst2020.07.225

Received originally: 09.03.2020

in revised form: 11.05.2020,

Accepted 13.05.2020,

Published 19.05.2020.

Keywords: autophagy, neurodegeneration, lipids, sphingolipids, phosphoinositols, Parkinson's disease, Alzheimer's disease.
Abbreviatons:
$\mathbf{A} \boldsymbol{\beta}$ - amyloid beta; AD - Alzhheimer's disease; $\mathbf{A P P}$ - amyloid precursor protein; $\mathbf{A S M}$ - acid SMase; C1P - Cer- 1-phosphate; Cer - ceramide; EAP - ethanolamine phosphate; ER - endoplasmic reticulum; GABARAP - $\psi$ - aminobutyric acid receptor-associated protein; GBA - glucocerebrosidase; GCS - GlcCer synthase; GIcCer - glucosylceramide; GUV - giant unilamellar vesicle; HD - Huntington's disease; iPSC - induced pluripotent stem cell; KO - knockout; LC3 - light chain 3; LSD - lysosoma storage disorder; LYNUS - lysosomal nutrient-sensing complex; MTM - myotubularin phosphatase family; mTOR - mammalian target of rapamycin; PD - Parkinson's disease; PE - phosphatidylethanolamine; PI - phosphatidylinositol; PI3K - PI-3 kinase; PI3P - Pl-3 phosphate; PICALM - PI binding clathrin assembly protein polyQ - polyglutamine; S1P - sphingosine-1-phosphate SM - sphingomyelin; SMase - sphingomyelinase; Sph - sphingosine; SphK - Sph kinase; TFEB - transcription factor $E B$.

\section{INTRODUCTION}

The prevalence of neurodegenerative disease like Alzheimer's (AD) and Parkinson's (PD) diseases will double in the coming years [1-3]. This is especially devastating since there is no cure nor effective treatment to stop the progression of most of these diseases. To revert this "no treatment/no cure" situation we need to gain a comprehensive understanding of the molecular mechanisms underlying the neurobiological basis of these diseases. Although neurodegenerative diseases are characterized by the appearance of very different symptoms caused by the particular disease's pathology, the abnormal accumulation of misfolded, dysfunctional and frequently aggregationprone proteins is a commonly observed phenomenon [4-9]. On the other hand, lipids are also essential regulators of brain function and there is emerging evidence pointing out a role of lipids in neurodegeneration derived from ageing or neurodegenerative pathologies [10-15]. Although only the minority of neurodegenerative disease are caused by monogenic inheritance, studies using transgenic animals with the genetic variant of the disease have been very helpful in identifying common cellular and molecular mechanisms impacting the onset of neurodegenerative disease. After more than 20 years of research, failure of 
protein and lipid quality control mechanisms and neuronal homeostasis are placed in the centre of neurodegenerative diseases $[16,17]$. In this context, autophagy has gained particular interest, since it can degrade cytosolic organelles and compartments [18-21] and has functional roles in lipid metabolism [22]. Moreover, lipids and lipid-binding proteins are essential components for the autophagosome formation and maturation. Emerging evidence shows that autophagy is altered in many neurodegenerative diseases and that defects in the autophagy pathway lead to the accumulation of dysfunctional and aggregation-prone proteins. Therefore, deciphering which step in the autophagy pathway is affected in a particular disease can shed light on the molecular mechanisms that lead to different pathologies and will provide an effective angle to develop diseasespecific therapies that target defective steps in the autophagy pathway.

Lipids are essential components of biological membranes, but are also involved in cellular signalling processes such as autophagy [23-26]. Technological advances in the recent years have partially overcome the challenges present in investigating the role of lipids in biological processes [27-29]. In this review we want to highlight the function of lipids in the autophagy pathway with a focus on how alterations of lipid metabolism affect autophagy and the role of lipid metabolism in neurodegeneration. The func- tion of lipids in neuronal homeostasis is starting to gather more attention but has not been discussed in great detail in connection with autophagy.

\section{AUTOPHAGY}

Autophagy is a catabolic pathway that degrades cytosolic content ranging from small particles to organelles like mitochondria. Three major autophagic pathways are known: micro- macro- and chaperon-mediated autophagy [30-34]. However, all three types converge within the lysosome to degrade cytosolic components and dysfunction in autophagy often leads to neurodegeneration [19, 20, 35]. In microautophagy the cytosolic components are translocated into the lysosome via direct invagination, protrusion or septation of the lysosomal membrane. In contrast, a selective degradation occurs during chaperon-mediated autophagy where proteins with a KFERQ-like motif are recognized and targeted for degradation by forming a complex with specific chaperones like HSC70 [36].These complexes are then recognized by the lysosomal receptor LAMP2A and directly translocated across the lysosomal membrane towards the lysosomal lumen, where degradation takes place. The third type is macroautophagy, which is essential for the degradation of defective organelles, proteins, aggregates, and even microorganisms. This process starts with the sequestration of a portion of cytoplasm creating

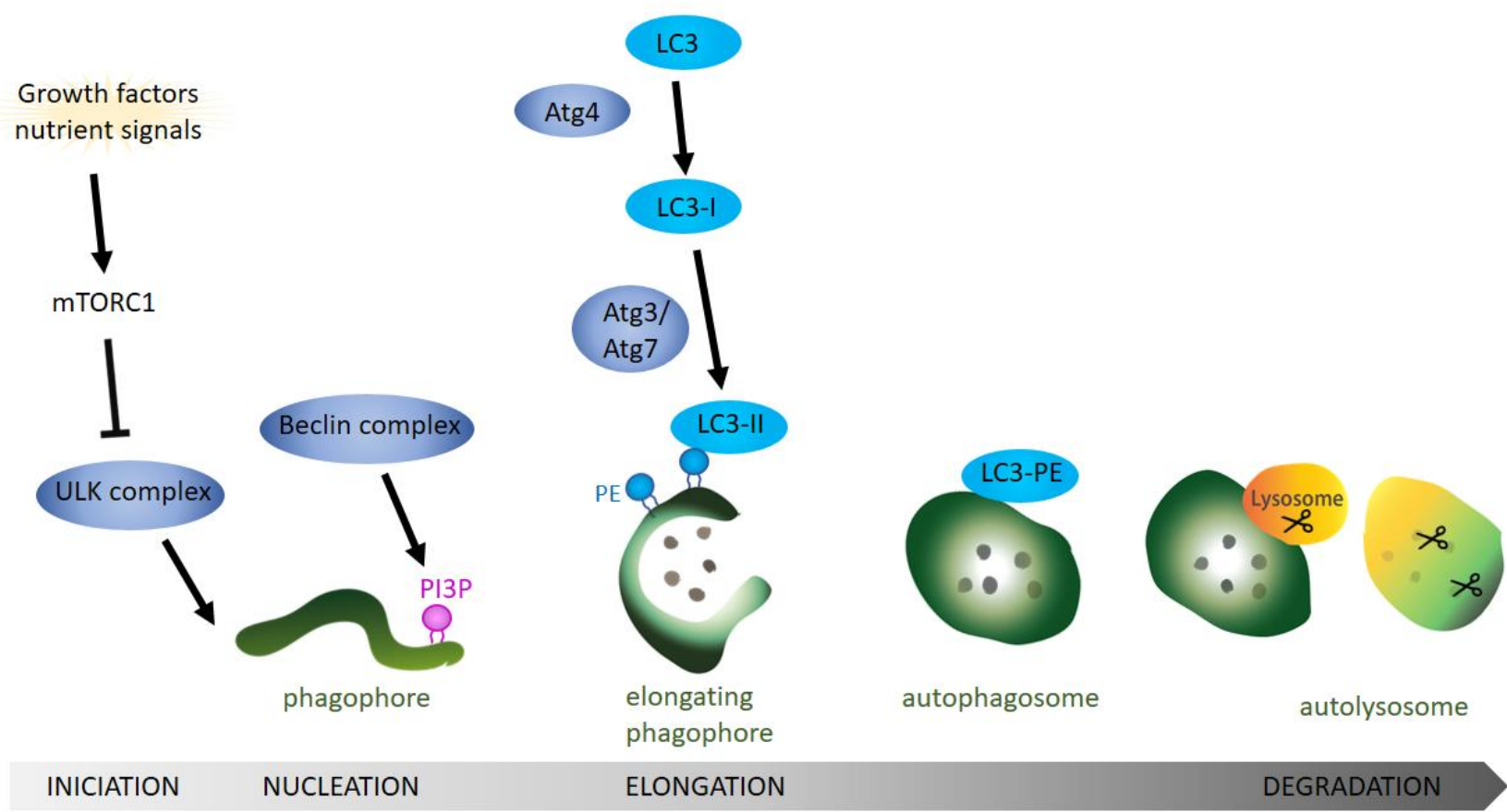

FIGURE 1: General overview of the autophagy pathway. Schematic drawing showing the autophagy process starting with the formation of the phagophore, followed by the completion of the autophagosome and finishing with the fusion of the autophagosome with the lysosome. Growth factors and nutrient signals inactivate the mammalian target of rapamycin complex 1 (mTOR1) leading to the activation and recruitment of the ULK complex to the phagophore. Activity of the Beclin complex leads to local enrichment of phosphatidylinositol-3-phosphate (PI3P). During the elongation of the phagophore, ATG4 processing of LC3 (ATG8 in Drosophila) and the subsequent conjugation to phosphatidylethanolamine (PE) on the phagophore membrane via ATG3 and ATG7 is essential step to form the autophagosome. After the fusion of the lysosome with the mature autophagosome, lysosomal proteases like cathepsin D degrade the autophagosomal content. 
an initial structure named the isolation membrane or phagophore [37] (Figure 1). The expansion of the phagophore and its closure around the cytoplasmic material give rise to the autophagosome. To degrade the target material, autophagosomes fuse with endosomes, creating amphisomes which then fuse with lysosomes to generate autolysosomes [38-41]. Lysosomes provide the hydrolases required to digest the content and the internal membrane of the autophagosomes into basic metabolites that can be reused to obtain new cellular components or energy [42, 43]. In yeast, autophagic membranes originate at the Phagophore Assembly Site (PAS) but in higher eukaryotic cells the origin of the autophagic isolation membranes is still not completely clear. However, mitochondria, the endoplasmic reticulum (ER), endosomes, the Golgi body and even the cytoplasmic membrane have been proposed as sources of autophagic membranes [44]. The precise molecular mechanisms of the autophagy pathway has already been extensively reviewed [45-48]. Next, we will focus on the role of lipids in the regulation of different aspects of the autophagy pathway.

\section{THE ROLE OF LIPIDS IN AUTOPHAGY}

Eukaryotic cell membranes are structured as lipid bilayers with glycerolipids, their phosphorylated derivatives, and sphingolipids as major components. Glycerophospholipids can be subdivided by their headgroups into five groups: phosphatidylcholine and phosphatidylethanolamine (PE) with a higher abundance and phosphatidic acid, phosphatidylserine and phosphatidylinositol (PI) with a lower abundance in the lipid bilayer. Phosphoinositides are phosphorylated phosphatidylinositols and have a major role in signalling events membrane trafficking (reviewed in $[49,50])$. Depending on the phosphorylation of the inositol ring we can distinguish seven different phosphoinositides: $\mathrm{PI}, \mathrm{PI} 3 \mathrm{P}, \mathrm{PI} 3,5 \mathrm{P}_{2}, \mathrm{PI} 5 \mathrm{P}, \mathrm{PI}, 4,5 \mathrm{P}_{3}, \mathrm{PI}, 4 \mathrm{P}_{2}, \mathrm{PI} 4,5 \mathrm{P}_{2}$ and $\mathrm{PI} 4 \mathrm{P}$ (Figure 2A). The presence and composition of phosphoinositides in the membrane creates the membrane identity of the organelle (Figure 2B) and offers specific protein binding sites for signalling events [51, 52].

Membranes play a pivotal role in the autophagic pathway. Unfortunately, the precise lipid composition of the intermediates in the autophagy process (phagophore, autophagosome, amphisome, autolysosome) are still unknown. We are also lacking information on whether the different membranes from which autophagosomes derive generate autophagosomes with different lipid composition. This knowledge gap may be due to the fact that most studies focus on the role of proteins in the dynamics of the autophagic pathway. However, in addition to the wellstudied lipid conjugation of light chain 3 (LC3)/ATG8, there is solid evidence that lipids such as phospholipids and sphingolipids also play a crucial role in the autophagy pathway.
A

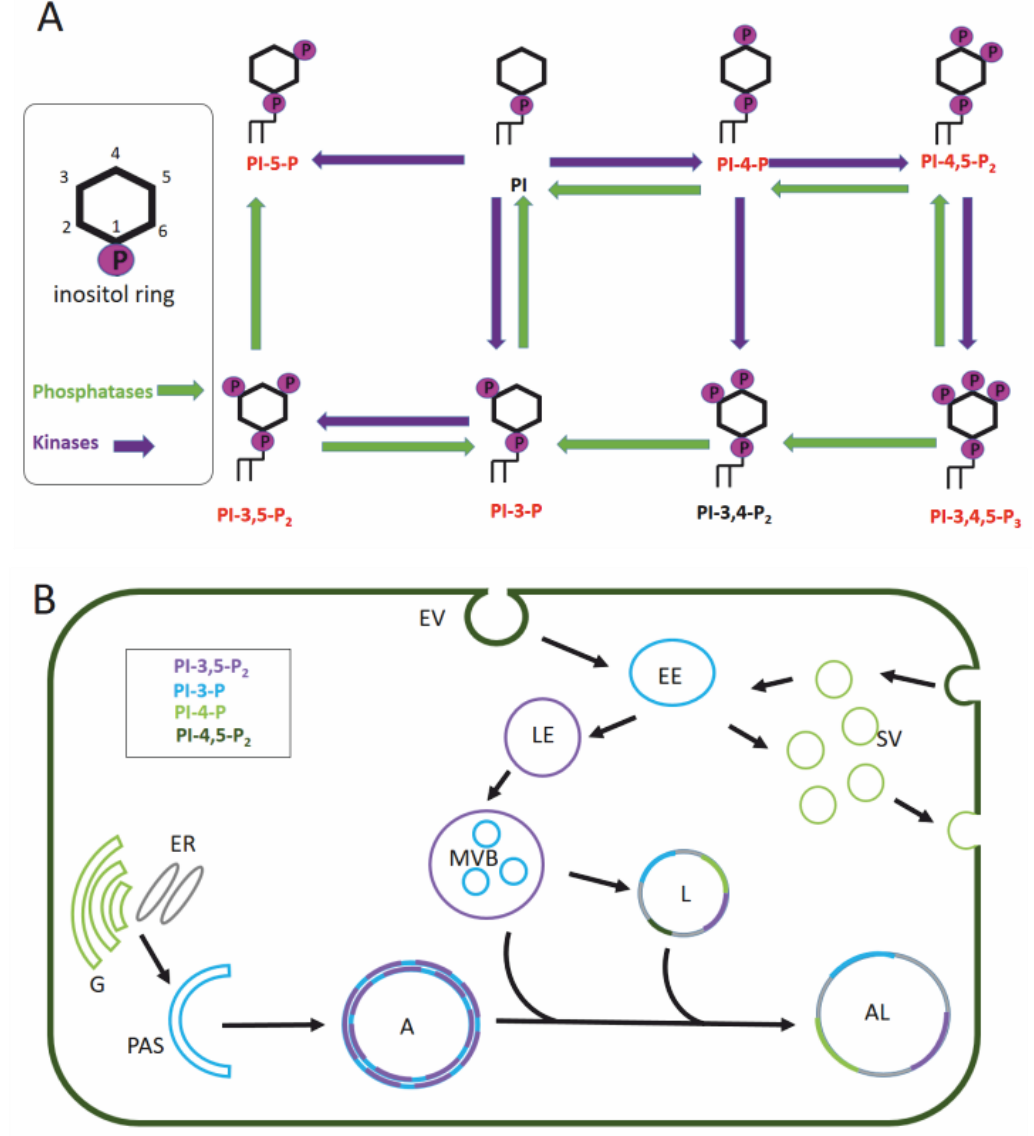

FIGURE 2: Phosphatidylinositol pathway and its role in cellular trafficking. (A) Phosphatidylinositols (Ptdlns) are small lipids, consisting of two fatty acid chains, a glycerol backbone and an inositol ring. Kinases (violet) can phosphorylate the inositol ring at various positions $(3,4$ and 5$)$ leading to different phosphoinositides. We can differentiate between phosphatidylinositol monophosphates (PI3P, PI4P, and PI5P), diphosphates $\left(\mathrm{PI} 3,4 \mathrm{P}_{2}, \quad \mathrm{PI} 3,5 \mathrm{P}_{2}, \quad \mathrm{PI} 4,5 \mathrm{P}_{2}\right)$, and a triphosphate $\left(\mathrm{PI}, 4,5 \mathrm{P}_{3}\right)$, that are substrates of different phosphatases (green) and kinases (see text for more details). Phosphoinositides that participate in the autophagy pathway are marked in red. (B) Membrane anchoring of the Ptdlns is possible thanks to its glycerol backbone that positions the inositol ring towards the cytoplasmic site. Therefore, Ptdlns often act as recognition motif for proteins containing a specific PI3P binding domain like pleckstrin homology $(\mathrm{PH})$, FYVE, WD40 repeats, FERM, PTB, and PDZ to mediate signaling pathways including autophagy and clathrin-mediated endocytosis. Moreover, the specific enrichment of Ptdlns can even mark the identity of intracellular organelles. Membranes are colored depending on postulated enrichment of specific phosphoinositols. PI4P enriched organelles are synaptic vesicles and Golgi, the phagophore and the early endosome are enriched in PI3P while the late endosome is enriched in $\mathrm{PI} 3,5 \mathrm{P}_{2}$. The multivesicular body, a specialized late endosome, and the autophagosome are $\mathrm{PI} 3,5 \mathrm{P}_{2}$ and $\mathrm{PI} 3 \mathrm{P}$ positive organelles. Once the autophagosome fuses with the lysosome, the resulting autolysosome becomes enriched in $\mathrm{PI} 3 \mathrm{P}, \mathrm{PI}, 5 \mathrm{P}_{2}$ and $\mathrm{PI} 4 \mathrm{P}$. Golgi (G), endoplasmic reticulum (ER), phagophore assembly site (PAS), autophagosome (A), autolysosome (AL), multivesicular bodies (MVB), lysosome (L), endocytotic vesicle (EV), early endosome (EE), late endosome (LE), synaptic vesicle (SV). 


\section{Function of glycerophospholipids in autophagy} The role of phospholipids in the initiation of autophagy In mammals, the ATG1 orthologue ULK1 recruits and forms a complex with ATG13, FIP200 and ATG101 [53]. Next, the integral protein ATG9 is incorporated to the nascent autophagosome via its interaction with FIP200 [54]. The Beclin 1 complex, also known as phosphatidylinositol-3 kinase (PI3K) complex, that consists of Beclin 1, VPS34 (the class III phosphatidylinositol-3 kinase), VPS15 (mammalian orthologue p150) and ATG14 (ATG14L) [55] is then recruited to the ER to promote nucleation of the phagophore following ATG9 incorporation. The CXXC motif of ATG14L is crucial for localization of the ATG14L and thus the Beclin 1 complex in the ER [56] where ULK1 phosphorylation of Beclin-1 occurs, thereby enhancing the kinase activity of VPS34 [55].

Interestingly, the enrichment of phosphatidylinositol(3)phosphate (PI3P) by VPS34 in the membrane is a key event in autophagy nucleation $[57,58]$. A locally enriched pool of PI3P serves to anchor proteins with PI3P binding motifs (see Review [59]), such as WIPI2 protein (WD-repeat protein interacting with $\mathrm{PI}$ ), which is necessary to elongate and close the autophagic membrane [60-62]. PI5P is also involved in autophagosomal formation in PI3P depleted cells by binding WIPI2 during glucose deprivation [25]. This and other alternative autophagic pathways still require further research to fully understand the role of autophagy in health and disease.

The elongation of and closure of the phagophore relies on glycerophospholipids

Recent work discovered that the N-terminal region of ATG2 presents structural similarity to VPS13, a lipid transporter that functions at vacuole- ER and vacuole-mitochondria contact sites [63] and this conserved motif mediates the targeting of ATG2 to the ER and is indispensable for autophagy [64-66]. The authors showed that ATG2A can bind multiple glycerophospholipids and, in turn, transport them between membranes. While there is still controversy concerning the protein partners and the molecular mechanism that modulates the ATG2 lipid transfer, a recent paper established that GABARAP ( $\gamma$-aminobutyric acid receptorassociated protein) is a crucial anchor protein for ATG2A whereas its binding to WIPI4 is not required in mammals for the formation and closing of the autophagosome [67]. Interestingly, other cellular compartments related with autophagosomes, like the endosomal compartment, are also enriched in PI3P and further research on the lipid transfer from these structures into the nascent autophagosomes would be necessary to fully understand the source of the autophagosomal membrane in different cellular compartments.

In the next step, the ATG16L1 complex, which includes the proteins ATG16L1, ATG5 and ATG12, is recruited to the pre-autophagosomal membranes. Structure-function analysis identified a conserved sequence within the coiled-coil domain of ATG16L1 that mediates its localization to preautophagosomal structures by direct binding with PI3P [68]. Moreover, in contrast to $\alpha$-isoform, the $\beta$-isoform of
ATG16L1 presents two membrane binding domains while the common $\mathrm{N}$-terminal membrane-binding amphipathic helix is required for LC3B lipidation the $\beta$-isoform also has a C-terminal membrane-binding region that is dispensable for canonical autophagy but essential for VPS34independent LC3B lipidation at perturbed endosomes [69]. The authors also demonstrate how the ATG16L1 C-terminus can sustain LC3 lipidation upon starvation also in the absence of WIPI2, indicating that these two isoforms may trigger autophagy in response to different cellular stimuli. The activity of the ATG16L1 complex promotes lipidation of LC3/ATG8 and GABARAP with PE [70-72]. Mutation in the lipid binding residues of ATG16L1 abolishes the conjugation/lipidation of LC3 to PE [68], which severely compromises the expansion and closure of the autophagosome, comparable with the phenotype observed in ATG8 mutants with the mutation G116A that abolishes any further lipidation. The ATG8 conjugation system is responsible for the lipidation of LC3/ATG8. This system works in a similar fashion to the ubiquitination system and comprises of the previously mentioned ATG5 and ATG12 together with ATG3, ATG4, and ATG7 proteins. ATG8 is cleaved by the cysteine protease ATG4 before being activated by ATG7 which acts like an E1 enzyme. ATG8 is then transferred to the $E 2$ equivalent ATG3 prior to the conjugation of the $P E$ that is carried by the ATG5-ATG12 complex acting as an E3 ligase [70,73]. Interestingly, the precise moment in which the conjugation of ATG8 occurs could be controlled by the curvature of the autophagic membrane structure. In vitro studies showed that the highly curved rim of the growing phagophore attracts autophagic complexes and serves as a platform where most of the ATG8/LC3 lipidation takes place. These highly curved membrane sites are recognized by curvature sensing domains in ATG1, ATG3 and ATG14/Barkor [74-76]. Although lipid packing depends on the particular headgroup type, when the lipids are part of highly-curved biological membranes, they are mostly organized in a loose packing fashion on the outer (convex) surface. Interestingly, poorly hydrophobic motifs that are common in "curvature-sensing" domains require loose lipid packing in the bilayer to favour the insertion of protein motifs into the bilayer [77]. The group of Thomas J. Melia showed that the N-terminal domain of ATG3 contains an amphipathic helix that inserts into highly curved membranes by sensing loose lipid packaging. Moreover using a liposome reconstitution assay they could directly show that this mechanism was crucial for LC3 lipidation [75]. The precise molecular mechanism dictating how preautophagosomal membranes become highly curved is less well understood. Endophilin-A, a protein enriched at the axon terminals, has for long been known to deform membranes during clathrin mediated endocytosis to assist in the formation of newly endocytosed synaptic vesicles [7881]. However, recently, Endophilin-A has also been implicated in autophagy at presynaptic terminals and this function is independent from its function in synaptic vesicle endocytosis [82]. LRRK2, a kinase that has been implicated in familial PD, phosphorylates Endophilin-A at Serine 75 within the central amphipathic helix of the N-BAR 
(Bin1/amphiphysin/Rvs167) domain [83]. This phosphorylation event changes the ability of Endophilin-A to interact with lipid bilayers [84]. The central amphipathic helix of Endophilin-A inserts deep into the acyl chains of the lipid bilayer, leading to a slight membrane curvature and the formation of tubules in an in vitro assay using giant unilamellar vesicles (GUVs). In contrast, phosphorylated Endophilin-A introduces a negative charge at Serine 75 , leading to a less deep insertion of the amphipathic helix into the lipid bilayer. As a result the lipid head groups are pushed apart, similar to the above discussed lipid packing defects, creating highly curved membranes [84]. In vitro membrane reconstitution assays on GUVs demonstrated that phosphorylated Endophilin-A leads to the creation of small highly curved membrane bends that attract ATG3 [82]. Moreover, in vivo studies in Drosophila using transgenic animals showed that ATG3 recruitment to preautophagosomal membranes is also dependent on Endophilin-A phosphorylation state at the presynaptic terminal and that this is critical of ATG8 lipidation.

Production of PI3P is a critical step in autophagy. Thus, PI3P acts as a master regulator of autophagy via its enrichment in endosomal and autophagic structures. PI3P can be generated from different substrates. PI3Ks can phosphorylate $\mathrm{PI}$ to produce different phosphatidylinositol phosphates. Class III PIK3s, such as VPS34, a member of the Beclin 1 complex, can phosphorylate PI to produce PI3P [58] but this class of kinases can also use PI together with $\mathrm{PI} \mathrm{P}$ and $\mathrm{PI} 4,5 \mathrm{P}_{2}$ to produce $\mathrm{PI} 3 \mathrm{P}, \mathrm{PI}, 4 \mathrm{P}_{2}$ or $\mathrm{PI} 3,4,5 \mathrm{P}_{3}$ respectively. Therefore, modulation of these enzymes is expected to impact autophagosome formation. For instance, PI3K inhibitors, like 3-MA (3-methyladenine), can block autophagy by inhibiting autophagosome formation. However, how these enzymes and their enzymatic products and substrates are regulated during autophagy is not well understood. Interestingly, PI3K enzymes respond to insulin and other growth factors that also modulate autophagy and the PI3K pathway plays a crucial role in cellular and tissue homeostasis and disease [85]. On the other side, inhibition of phosphatases that dephosphorylate $\mathrm{PI}_{3}, 4,5 \mathrm{P}_{3}$ (such as PTEN) or the addition of synthetic $\mathrm{PI}, 4,5 \mathrm{P}_{3}$ can inhibit autophagy in cell culture [86]. Notably, the inhibition of autophagy caused by the loss of PTEN function does not affect the lipidation levels of ATG8/LC3.

Local production of PI3P due to class III PI3K activity has been proposed as one of the first steps necessary for the phagophore formation in mammals and other organisms [56]. This local concentration of PI3P may act as docking station for proteins with FYVE domains like DFCP1, GAPR1, WIPI or the Drosophila protein Zonda, that bind to PI3P [87]. These proteins are essential in the early steps of autophagosome formation and local concentration of PI3P is therefore critical for the initial steps of autophagosome formation.

$\mathrm{PI3P}$ function is also essential for the maturation of the autophagosome to generate amphisomes (autophagosome fused to endosomes) which, in turn, fuse with lysosomes to generate the autophagolysosome $[88,89]$.
Besides formation and maturation of autophagosomes and autophagolysosomes, PI3P lipids do also contribute to the autophagosome localization and transport. The mammalian motor protein FYCO1 binds PI3P through its FYVE domain and mediates plus-end microtubule transport of autophagosomes towards the endolysosomal system. Depletion of FYCO1 results in the perinuclear accumulation of autophagosomes [90]. Interestingly, this protein also interacts with LC3 and Rab7 and mediates anterograde transport of endocytic components via the kinesin Kif5 [91]. However, how the local concentrations of PI3P and FYCO1 precisely work in the connection of the autophagy and endosomal systems would require further investigation.

The role of PI3P is not restricted to bulk macroautophagy, as for instance PI3P is also necessary to localize Alfy, the mammalian orthologue of the Drosophila Blue Cheese, and TECPR1 in selective autophagy to eliminate aggregates and bacteria [92]. Interestingly, another phosphoinositide that may impact initiation of the autophagosome is PI4P, a lipid that recruits ATG13, a subunit of the ULK1 complex, to the nascent autophagosomes. Under starvation conditions, ATG9 positive vesicles enriched in BAR-domain containing proteins like arfaptins (ADP ribosylation factor interacting protein), and phosphoinositide metabolizing enzymes including the PI4K3 beta kinase facilitate the local production of PI4P [93].

\section{Turnover of phospholipids is required for autophagosomal maturation}

While the initial accumulation of PI3P on the phagophore is essential for the recruitment of some ATG proteins, the maturation step requires the removal of these ATG proteins from the autophagosome. Interestingly, a switch in the phospholipid composition in the nascent autophagosome is crucial for this protein removal. The first indication of this phenomenon came from yeast, where Ymr1 Ptdlns3P phosphatase activity is required to turn over PI3P and to release the ATG proteins from the mature autophagosome [94]. The myotubularin phosphatase family (MTM) has emerged as a key family of phosphatases controlling PI3P levels and therefore controlling autophagy. For instance, the absence of MTM1 results in activation of mTORC1 [95] and several myotubularin-related phosphatases are reported to control different stages of autophagy, such as MTMR-14 / Jumpy controlling initiation steps in autophagosome biogenesis [96] and MTMR-3 regulating autophagosome biogenesis and size [97]. Unexpectedly, the ability of MTMR to control autophagy also relies on members whose catalytic domain is not functional. For example, the catalytically inactive MTMR-9 determines the enzymatic activity and specificity of MTMR- 8 in autophagy in HeLa cells [98]. Further research addressing how these phosphatases regulate autophagy in neuronal cells and during neurodegeneration will be essential to better understand the importance of phospholipids turnover, autophagy and brain (dys)function.

The presynaptically enriched protein synaptojanin 1 (Synj1) is a lipid phosphatase well known for its function in synaptic vesicle endocytosis $[29,99-101]$ that has recently 
been shown to function in autophagy at presynaptic terminals [102]. Synj1 targets different polyphosphoinositides with its two distinct lipid phosphatase domains: 5-phosphatase which targets $\mathrm{PI}, 5 \mathrm{P}_{2}[103,104]$ an important phosphoinositol in clathrin mediated endocytosis; and SAC1 which targets PI3P, PI4P, and PI3,5P 2 [105], phosphoinositols with reported functions in autophagy. $A$ PD causing mutation (R258Q) within the SAC1 domain of Synj1 [106-108] leads to the accumulation of immature autophagosomes at the presynaptic terminal in human neurons differentiated from patient-derived induced pluripotent stem cells (iPSC) [102]. Using transgenic Drosophila models of PD with a knock-in mutated Sac1 domain established that Synj1 removes the $\mathrm{PI} \mathrm{P} / \mathrm{PI}, 5 \mathrm{P}_{2}$ binding protein WIPI2/ATG18a from immature autophagosomes (Figure 3). In synaptic vesicle endocytosis Synj1 hydrolyses $\mathrm{PI} 4,5 \mathrm{P}_{2}$ causing the removal of adaptor proteins, including clathrin, from newly endocytosed vesicles. In autophagy, like in endocytosis, the release of the adaptor proteins from the organelle seems to be important for the maturation and trafficking of the organelle.

In brief, the presence and local production of the phospholipids like PI3P is critical to define the origin of autophagic membranes, as well as to recruit key protein complexes acting in autophagosome biogenesis, maturation and trafficking. The removal of specific phospholipids and/or their conversion to a different phospholipid species are also critical steps for the proper maturation and function of the autophagosomes.
The role of phospholipids in auto-lysosomal fusion The presence of $\mathrm{PI}, 5 \mathrm{P}_{2}$ is low in late endosomes and lysosomes. In neurons, conversion of $\mathrm{PI} 3,5 \mathrm{P}_{2}$ to $\mathrm{PI} 3 \mathrm{P}$ by inositol polyphosphate-5-phosphatase-E (INPP5E) promotes lysosomal fusion with the autophagosome [89]. However, $\mathrm{PI} 3,5 \mathrm{P}_{2}$ seems to have a very important role in these organelles regulating calcium signalling and autophagy through the TRPML1 ion channel [109]. While PI3,5P 2 may work as an activator, another $\mathrm{PI}, \mathrm{PI}, 5 \mathrm{P}_{2}$, seems to inhibit TRPML channels [110]. In this context it is worth mentioning that TRPML1 acts as a ROS (reactive oxygen species) sensor on lysosomal membranes involved in autophagy induction and that TRPML1 function is required for autophagosomal and lysosomal biogenesis [111]. Interestingly, cells from Niemann-Pick C (a lysosomal storage disease) disease's patients show reduced levels of activity in the TRPML1 and mutation of TRPML1 leads to the lysosomal storage disease, mucolipidosis type IV [112]. Interestingly, some lysosomal storage disorders are characterized by abnormal storage of various phospholipids due to reduced sphingolipid catabolism, but whether the local unbalance of phospholipid is a primary cause and how it may result in these disorders is still unclear.

The autophagosome-lysosome fusion event also relies on the GABARAP dependent recruitment of phosphatidylinositol 4-kinase Il $\alpha$ for PI4P production on autophagosomes [113]. On the other side PI4P conversion to $\mathrm{PI} 4,5 \mathrm{P}_{2}$ on late endosomes leads to dissociation of Rab7 and, consequently, the release of pleckstrin homology domaincontaining family $\mathrm{M}$ member 1 (PLEKHM1), a regulator of autophagosome-lysosome fusion [114].

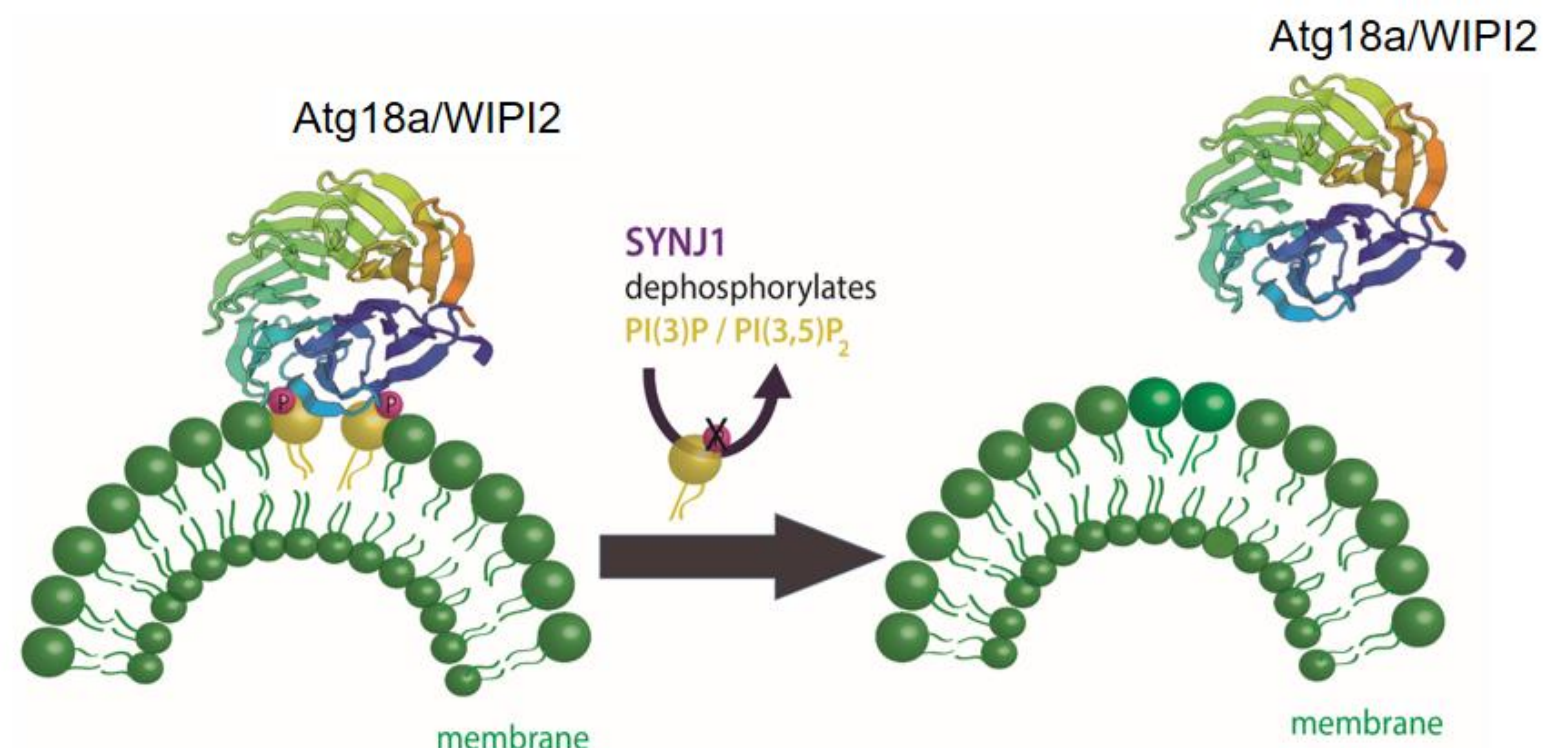

FIGURE 3: Maturation of autophagosomes relies on the turnover of PI3P/PI3,5P ${ }_{2}$ on autophagosomal membranes. In the initial phase of the autophagy pathway the accumulation of PI3P on the phagophore is required to recruit ATG18 and its mammalian homologue WIPI2. The WD40 domain in ATG18/WIPI2 folds into a seven bladed beta-propeller that contains two phenylalanine-arginine-arginine-glycine (FRRG) motifs in the sixth blade. This FRRG residue is a two sided recognition motif with binding specificity to PI3P/PI3,5P . Maturation of nascent autophagosomes requires the shedding of autophagic factors like ATG18/WIPI2. At the presynaptic terminal, the phosphatase synaptojanin1 (Synj1) dephosphorylates PI3P/PI3,5 $\mathrm{P}_{2}$ on autophagosomal membranes leading to the removal ATG18/WIPI2. Shedding of autophagic factors like ATG18/WIPI2 from the autophagosome is important for progression of the autophagic pathway. 


\section{Function of sphingolipids in autophagy}

Sphingolipids are a family of lipids that use a sphingoid base as structural backbone. They are structural components of biological membranes where they can modulate the rigidity of membranes and participate in signalling to downstream effectors (for review see [115]). The de novo synthesis of sphingolipids starts at the ER and ultimately generates ceramide (Cer), a central component of sphingolipid metabolism. While sphingomyelinase (SMase) catalyses the generation of ceramide from sphingomyelin (SM), the enzyme glucosylceramide synthase (GCS) catalyses the synthesis of glucosylceramide (GlcCer) from Cer, the initial step of glycosphingolipid biosynthesis. Cer can also be deacylated to form sphingosine (Sph), which in turn is phosphorylated by sphingosine kinase (SphK) to sphingosine-1-phosphate (S1P) (Figure 4). Cleavage of S1P by the sphingosine 1-phosphate lyase1 (SGPL1) to fatty aldehyde and ethanolamine phosphate (EAP) is an exit from the complex sphingolipid network. Here, we will concentrate mainly on the bioactive sphingolipids Cer and S1P that have been shown to regulate mainly the initial steps of the autophagy process (Figure 5).

\section{Sphingolipids acting at the stage of autophagy induction} Cer can initiate autophagy by lowering the uptake of nutrients like amino acids into the cell [116] leading to the acti- vation of AMPK, upregulation of Beclin 1 and blocking mTORC1 [117]. Furthermore, Cer can also have an indirect role in autophagy initiation via GlcCer. Both pharmacological inhibition and siRNA-mediated reduction of the abundance of GCS, the enzyme that converts Cer to GlcCer, independently decrease AKT phosphorylation, thus blocking mTOR (mammalian target of rapamycin) and increasing autophagy levels [118].

Interestingly, a type of sphingomyelinase that respond to stress and amino acid deprivation is the acid sphingomyelinase (ASM), a class of SMase located at the lysosome that generates Cer from SM, leading to increased Cer levels. Furthermore, amino acid deprivation induces autophagy with an increase in ASM and Cer in human leukaemia cells, where knockdown of this enzyme suppresses autophagy induction [119]. However, increased ASM activity is also linked to abnormal autophagic degradation and brain pathology [120]. How ASM functions in the regulation of autophagy in neuro-degenerative diseases is still far to be completely understood. A recent publication shows that ASM is a negative regulator of autophagy via the lysosomal nutrient-sensing complex (LYNUS), a central multiprotein complex located in the lysosomal membrane that includes mTOR and the transcription factor EB (TFEB). LYNUS ensures cellular survival during amino acid deprivation and stress by regulating autophagy and protein synthesis. ASM

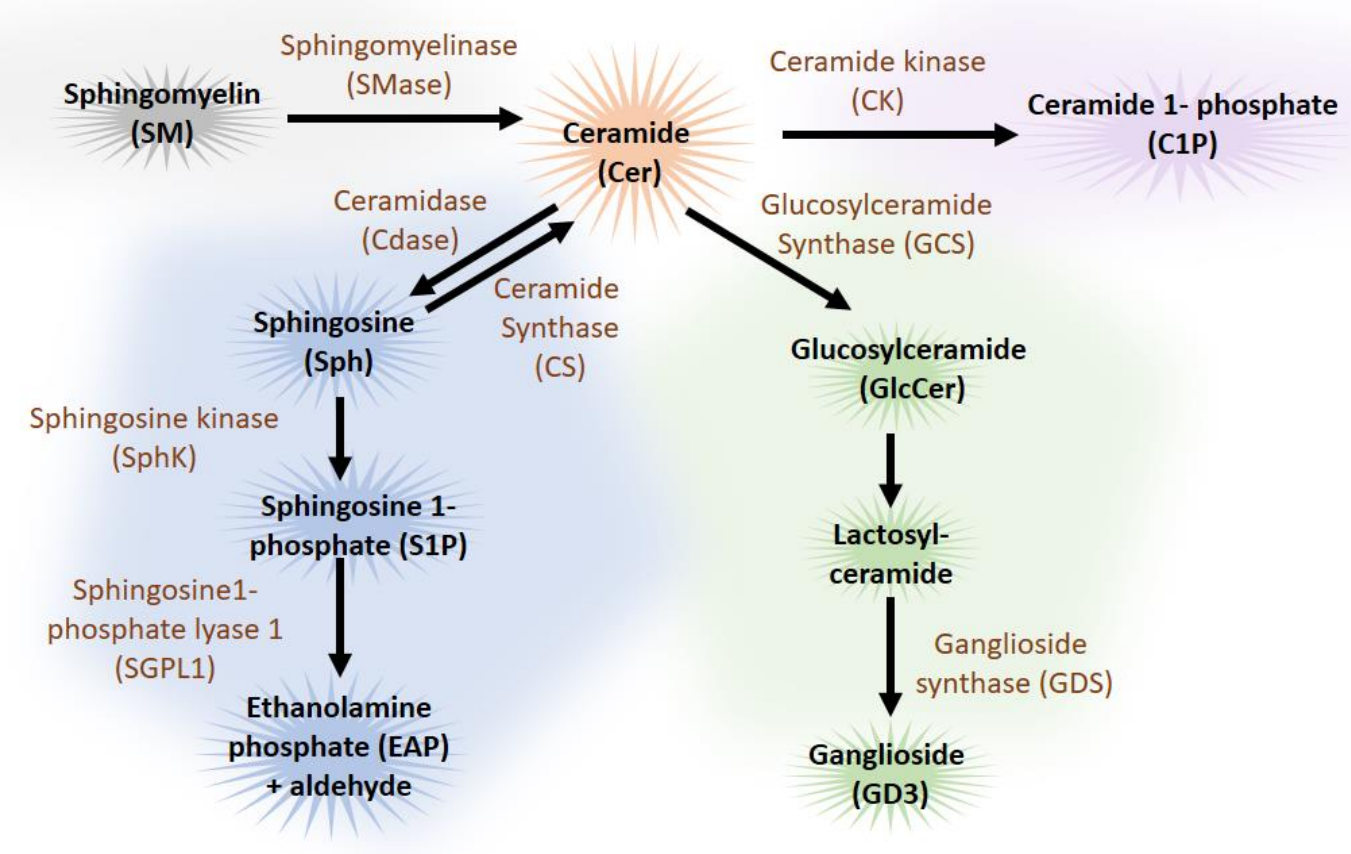

FIGURE 4: Overview of sphingolipid metabolism pathway. Ceramide (Cer) occupies a central position in the catabolic (blue), the sphingomyelin (grey) and hydrolytic (green) sphingolipid pathways. Apart from the de novo synthesis, ceramide can also be synthesized from sphingomyelin (SM) by sphingomyelinase (SMase) or from sphingosine (Sph) by ceramide synthase (CS). Cer can be catabolized to the biologically active metabolites, sphingosine (Sph) and sphingosine 1-phosphate (S1P) and further catabolized to ethanolamine phosphate (EAP) and C16 fatty aldehydes by ceramidase (Cdase) by the sphingosine kinase (SphK) and sphingosine1-phosphate lyase 1 (SGPL1) respectively. Cer can also be hydrolysed by glucosylceramide synthase (GCS) to glucosylceramide (GlcCer) and by ganglioside synthase (GDS) to ganglioside (GD3), a complex glycosphingolipid. Phosphorylation of Cer by the ceramide kinase (CK) produces ceramide-1-phosphate (C1P). Sphingolipids are coloured in black and enzymes are coloured in brown. (Note only autophagy relevant parts of the sphingolipid pathways are illustrated.) 


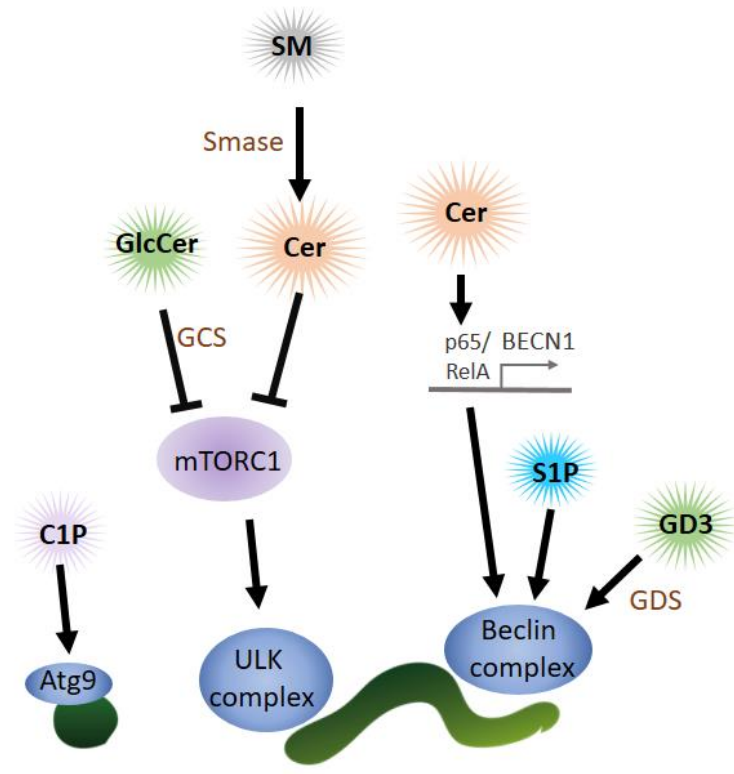

INICIATION NUCLEATION

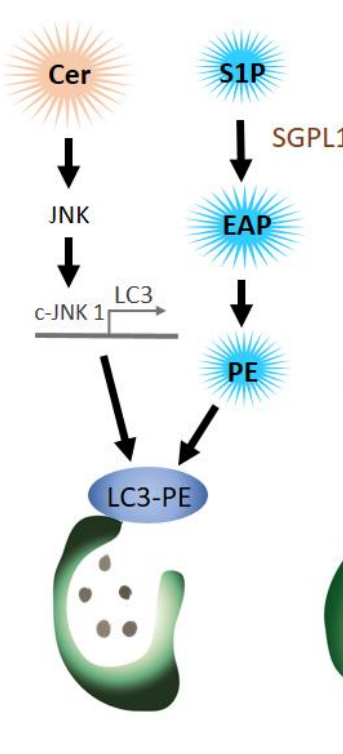

ELONGATION

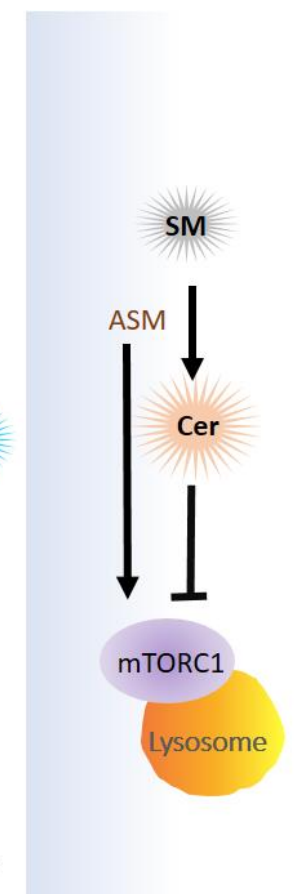

FIGURE 5: Bioactive sphingolipids, ceramide and sphingosine-1-phosphate (S1P) regulate autophagy especially in the initial steps. Lipids from the catabolic (blue), the sphingomyelin (grey) and hydrolytic (green) sphingolipid pathways function in the autophagy pathway. Sphingomyelin (SM) conversion to ceramide (Cer) by sphingomyelinase (SMase) affects mTORC1 activity on the lysosome and also on the phagophore. Cer can also induce autophagy by activating the transcription of ATG, BECN1 (Beclin) and LC3. Glycosphingolipids, glucosylceramide (GlcCer) and ganglioside (GD3) affect the autophagy pathway via mTORC1 or the Beclin complex respectively. LC3 conjugation to phosphatidylethanolamine $(\mathrm{PE})$ is modulated by the catabolic sphingolipid pathway since sphingosine-1-phosphate (S1P) conversion to ethanolamine phosphate (EAP) that can be further converted to PE. During auto-lysosomal fusion Cer and SP1 have opposing effects (See text for details). Ceramide (Cer), sphingomyelin (SM), sphingomyelinase (SMase), acid sphingomyelinase (ASM), glucosylceramide (GlcCer), glucosylceramide synthase (GCS), ganglioside (GD3), sphingosine-1-phosphate (S1P), sphingosine-1-phosphate lyase 1 (SGPL1), ethanolamine phosphate (EAP), phosphatidylethanolamine (PE).

control of the integrity of the LYNUS complex is required to maintain physiological functions of lysosomes. Notably, the reduction of ASM activity leads to the disruption of the LYNUS complex and activation of TFEB that then initiates the expression of lysosomal hydrolases and genes involved in autophagy while simultaneously reducing levels of Sph and S1P [121]. Taken together, although Cer is a positive regulator of autophagy, ASM abundance and activity can also impair autophagic degradation and physiological levels of this enzyme at the lysosome may prevent autophagy induction by controlling mTOR function at the level of the LYNUS complex.

Sphingolipids interactions during nucleation of autophagy The ER-mitochondria contact site can function as a membrane donor for the phagophore. Lipid microdomains, so called lipid rafts, in ER-mitochondrial contact sites have recently been shown to be critical for this process. Ganglioside GD3, a building block of lipid rafts, associates with AMBRA1 and WIPI1, part of the Beclin complex, during autophagy initiation $[122,123]$. The authors claim that GD3 in lipid rafts not only recruits autophagic factors but also contributes to membrane fluidity controlling this critical factor in the formation of highly curved membranes on the phagophore.

Cer can also initiate autophagy directly by activating the expression of Beclin 1 (BECN1) [117]. Copetti and coworkers stated that BECN1 expression is regulated by the NF-KB family member p65/RelA and consequently activation of p65/RelA enhances autophagy [124]. In line with these results another group showed that Cer can trigger p65 activation $[125,126]$. In conclusion, Cer mediates the binding of $p 65 /$ RelA with the $\mathrm{KB}$ binding site in the first intron of BECN1 and thereby activates the expression of BECN1. In addition to the Cer function in BECN1 expression, Cer also promotes dissociation of the Bcl2-Beclin $1 \mathrm{com}$ plex by the c-Jun $\mathrm{N}$-terminal protein kinase 1 (c-JNK 1) [127]. Activation of c-JNK 1 leads to phosphorylation of a non-structural $\mathrm{N}$-terminal loop of $\mathrm{Bcl}-2$ that is necessary for the association with Beclin 1. Dissociation of $\mathrm{Bcl}-2$ from Beclin triggers the induction of autophagy. At this point, it is important to highlight that ceramides can also function as soluble (or partially soluble) molecules when they are in the form of short-chain Cer. Indeed, because of their solubility in aqueous media, most in vitro experiments have used the short-chain forms as an exogenous source of Cer to investigate Cer's biological roles. For instance, the con- 
version of short-chain Cer into long-chain Cer by ceramide synthase is required to trigger autophagy [117] while it has been reported that treatment with exogenous short-chain ceramides and pharmacological treatments result in a comparable increase of endogenous Cer levels [116].

There is emerging evidence indicating that Cer activates gene expression of ATG genes like LC3. Experiments in the digestive tract of Drosophila showed that activation of the JNK pathway triggers autophagosome formation and a genetic interaction between JNK and ATG genes [128]. Moreover, inhibition of JNK signalling blocked Cer-induced autophagy and LC3 expression [129].

SP1 also positively regulates the Beclin complex but the precise mechanisms remain elusive. Overexpression of Sphk in primary neurons, leads to the production of SP1 and enhances the formation of preautophagosomal Beclin 1-positive structures and thus increases the formation of autophagosomes [130].

\section{Elongation of the phagophore depends on sphingolipid interaction}

In light of the debate about the origin of the donor membrane of the autophagosome, ATG9-positive vesicles may donate material to the elongating phagophore [131]. This stage can also be impacted by the availability of ceramide1-phosphate (C1P), the phosphorylated form of Cer. C1P promotes liposome fusion [132] and might enhance the formation of Golgi-derived ATG9 vesicles that subsequently fuse at the phagophore [133]. Counteracting the activity of S1P, SM accumulation in recycling endosomes impairs ATG9 trafficking and as a consequence preautophagosomal structure cannot mature to form an autophagosome [134].

S1P levels can have a dramatic effect on autophagosomal formation by affecting the lipidation of LC3 to the autophagosomal membrane. Developmental depletion of sphingosine-1-phosphate lyase 1 (SGPL1) specifically in the nervous system leads to increasing levels of S1P without affecting other sphingolipid metabolites like Cer or SM [135]. S1P cleavage by SGPL1 into EAP and aldehyde is considered an exit point of the sphingolipid pathway. Phosphate cytidylyltransferase 2 (PCYT2) can than convert EAP to CDP-ethanolamine and subsequent reaction by a methyltransferase leads to the production of PE [135]. A posttranslational lipidation reaction can then conjugate LC3 to $\mathrm{PE}$ on the phagophore. This article indicates that restoring physiological PE levels, either by adding exogenous PE or using pharmacological approaches, could be used to rescue autophagy-defects caused by PE deficit. Indeed, addition of $P E$ can reduce the accumulation of aggregate prone proteins such as APP (amyloid precursor protein) and SNCA ( $\alpha$ synuclein) in primary cultured neurons and in hippocampal slices from conditional SGPL1 knockout (KO) mice, indicating that PE supplementation may be a suitable therapeutic approach [135].

\section{The function of sphingolipids in the degradation of autoph agosomal cargo}

Even though sphingolipids have not been shown to directly promote fusion of the autophagosome with the lysosome to form the autolysosome, various studies have implicated sphingolipid metabolites in the degradative step of the autophagy pathway. Some sphingolipids like Cer with a chain length $\mathrm{C} 18$, can mediate target-specific degradation of mitochondria by autophagy [136, 137]. Cer on mitochondria can bind lipidated LC3 on autolysosomal membranes and promote mitophagy [138].

Sphingolipids can mediate the degradation of particular targets, but they also serve as autophagic substrates. This has been observed in epithelial cancer cells where K-Ras mediates autophagic S1P degradation [139]. Blocking autophagy in these cancer cells restores S1P localization and apical extrusion, an apoptotic process that maintains epithelial barriers and suppresses the spreading of cancer cells into the surrounding tissue.

In brief, sphingolipids like Cer or SP1 play an important role in autophagy by regulating autophagosome biogenesis, maturation and autophagosome-lysosome fusion, a critical step for the degradation of the autophagosome cargo.

\section{AUTOPHAGY AND NEURODEGENERATION: A LIPID PERSPECTIVE}

The mutation of genes involved in the regulation of autophagy are frequently associated with neurodegenerative diseases (review in [140]). Studies using KO models of core autophagy genes (atg5 and atg7) in flies and mice showed that autophagy is critical for neuronal survival [19, 141, 142]. Conditional KO of atg5 in neurons causes motor dysfunction and abnormal accumulation of proteins and aggregates in the cytoplasm [141]. Loss of ATG7 specifically in the central nervous system of mice also impairs motor function and leads to neurodegeneration and early death. Interestingly, two studies showed that these mice accumulate polyubiquitinated aggregates, a hallmark of many neurodegenerative diseases caused by autophagy dysfunction. In addition, these mice also accumulate abnormal levels of SNCA and LRRK2 [20], the two major components of the PD-associated Lewy bodies [4, 5]. Moreover, variations in the locus of atg5 and atg7 are risk factors for PD [143, 144] However, the precise molecular mechanism occurring between defective autophagy and the onset of neurodegeneration remains elusive.

As previously mentioned, the appearance of protein aggregates in the brain is a hallmark of many neurodegenerative diseases including $A D, P D$, amyotrophic lateral sclerosis, and Huntington's disease (HD). While the amount of protein aggregation correlates positively with neurotoxicity, the importance of understanding clearance mechanisms in neurons became evident when Yamamoto et al. demonstrated that a constant influx of the pathological huntingtin protein was required for the disease, indicating that clearance of these aggregates could alleviate symptoms of neurodegenerative diseases [145]. Later, Hara et al. demonstrated that autophagy was one of these essential clearance mechanisms to prevent accumulation of inclusion bodies in neurons [141]. Autophagic clearance of protein aggregates requires cargo receptors like sequestosome 1 (SQSTM1/ p62), NBR1, optineurin (OPTN), and NIX/BNIP3L, 
that sequester these aggregates to the autophagosome [146-149]. Several aggregate prone proteins, like ataxin-1 (SCA1) and ataxin-3, polyglutamine (polyQ)-repeated huntingtin, aggregate-prone $\alpha$-synuclein A53T and A30P mutants, tau and SOD1 (copper/zinc superoxide dismutase) are predominately degraded by the autophagy pathway [150-154].

Autophagy plays a crucial role in neural homeostasis since specific suppression of autophagy in the central nervous system leads to neurodegenerative phenotypes $[19,141]$ and disruption of this pathway in dopaminergic mice neurons promotes presynaptic accumulation of "Parkinson's proteins" like LRRK2 and $\alpha$-synuclein [155].

Interestingly, macroautophagy is a central process in the clearance of neuro-pathological aggregates in several neurodegenerative diseases. For instance, macroautophagy reduces the toxic level of aggregates caused by the accumulation of mutant huntingtin, $\alpha$-synuclein and tau in vitro as well as in vivo Drosophila and mouse disease models $[150,153,156,157]$.

\section{Function of phospholipids in neurodegeneration}

We have described how phospholipids are important for the biogenesis of autophagosomal structures. Hence, regulation of local levels of the different phospholipids specimens is important for this early autophagosome biogenesis. For instance, autophagosome formation can therefore be positively or negatively regulated by PI3P kinase complex or MTMR phosphatases respectively.

\section{Phosphoinisitol metabolism in amyotrophic lateral sclerosis and Charcot-Marie-Tooth disease \\ Mutations in the phosphoinositol $(3,5)$ bisphosphate $5^{\prime}$ phosphatase Fig4 lead to neuronal degeneration in rodent brains and has been associated to neurodegenerative dis- ease in humans, including a recessive form of Charcot- Marie-Tooth disease type $4 \mathrm{~J}$ and amyotrophic lateral scle- rosis [158]. Likewise, mice with a mutant Vac14, one of the enzymes required for $\mathrm{PI}(3,5) \mathrm{P}_{2}$ synthesis, also suffer from the loss of neurons [159]. These defects could be associat- ed with the alterations of the autophagic pathway, since Fig4 and Vac14 mutant mice show accumulation of lipi- dated LC3 - a hallmark of autophagy activation - and LAMP2 in neurons and astrocytes [160]. Noticeably, the accumulation of p62 and ubiquitinated proteins is more prominent in the brain regions that show high neuronal death. However, how Fig4 regulates autophagy is still far from being understood. For instance, Fig4 does also regu- late lysosome size independent of the phosphatase activity in muscle of invertebrate models [161]. However, this non- catalytic function of Fig4 has not been yet investigated in neurons or mammalian models of the disease.}

\section{Deregulation of phospholipids in $H D$}

Decreasing the activity of PIP4KY in mice primary neurons expressing mutant huntingtin protein in human patient fibroblasts leads to an increase in PI5P, PI3,5 $\mathrm{P}_{2}$ and $\mathrm{PI} 3 \mathrm{P}$ levels that positively stimulate basal autophagy and the degradation of aggregates and polyQ proteins. This is par- ticularly interesting since pharmacological inhibition of PIP4K $y$ with the compound NCT-504 could potentially have therapeutic applications [162]. Moreover, the overexpression of huntingtin can stimulate autophagy and endolysosomal systems in neurons [163] and the polyQ expansion in the pathological form of huntingtin can change the phospholipid binding affinity of the huntingtin protein [164] which may explain why huntingtin localizes to endolysosomes and autophagosomal structures in neurons from HD patients [163]. Further research is necessary to understand if mutant huntingtin pathology can, at least partially, resided at the level of phospholipid interaction.

\section{Dysfunction of phospholipids in PD}

Lipidomics of human primary fibroblasts from PD patients with a Parkin mutation, revealed that gangliosides, $\mathrm{PI}$ and phosphatidylserine levels were increased [165]. The authors suggest that this could be the result of autophagic alterations that have been extensively studied in Parkin mutant animal models. Although these results were not obtained in brain samples, the ubiquitous function of Parkin within the mitochondria may indicate these levels are also increased in the brain. Contrary, another report indicates that mitochondria from aged Parkin null mice brain show reduced levels of diverse types of phospholipids [166]. However, the mechanisms acting at pathophysiological level for defective phospholipid homeostasis in PD patients harbouring Parkin mutations need to be further studied.

As mentioned before, mutations within the SAC1 domain (R258Q and R459P) of Synj1 inhibit the phosphatase function of the SAC1 domain and cause early onset PD [106-108]. Knock-in flies with the R228Q mutation in Synj1 (the corresponding pathogenic mutation to R258Q in flies) show age-dependent neurodegeneration of dopaminergic neurons, activity-dependent neurodegeneration of photoreceptors and accumulation of immature autophagosomes [102], indicating that the function of the SAC1 domain is necessary for autophagy and required for neuronal survival. The function of the synaptic protein Endophilin-A is also critical for neuronal survival in mice and flies [80, 82, 167] and variation at the Endophilin-A1 locus (SH3GL2) is proposed to be a risk factor for PD [168]. We have already discussed that the Parkinson protein LRRK2 phosphorylates Endophilin-A and that insertion of phosphorylated Endophilin-A into the lipid bilayer leads to more wedging of the lipid head group and creates highly curved membranes that attract ATG3. Interestingly, similar to Synj with the R228Q, phosphomimetic and phosphodead Endophilin-A also leads to neurodegeneration of dopaminergic neurons and photoreceptors [82].

\section{The role of phospholipids in $A D$}

Progressive loss of memory, the appearance of amyloid $\beta$ $(A \beta)$ aggregates in plaques, and hyperphosphorylated tau as neurofibrillary tangles in the brain are all hallmarks of $A D$, the most common neurodegenerative disease. Post mortem analysis of $A D$ patient brains revealed a reduction of $\mathrm{PIP}_{2}$. The authors of this study claim that this reduction 
was a result of increased levels of Synj1 that is known to dephosphorylate $\mathrm{PIP}_{2}$ during clathrin-mediated endocytosis [169]. Another study showed that deregulation of $\mathrm{PIP}_{2}$ levels in $A D$ mice models has an effect on neurotransmission, spatial learning, and memory [170]. Although the idea of using phospholipid levels as diagnostic or prognosis readout have been explored, there are evidences suggesting that changes of phospholipids are not detected in early stages of the disease [171] although screening using stateof-the-art lipidomics of blood or cerebrospinal fluid would be worthy to explore.

Genome-wide association studies have recently identified PICALM/CALM (phosphatidylinositol binding clathrin assembly protein) loci associated with increased $A D$ development risk [172]. PICALM directly interacts with $\mathrm{PIP}_{2}$ on the plasma membrane during clathrin mediated endocytosis. Genetic evidence of PICALM as a risk factor for AD was further confirmed by revealing that the adaptor complex AP2 and PICALM interact with LC3 to mediate the degradation of Alzheimer's C-terminal fragment APP via autophagy [173]. Moreover, Zebrafish and Drosophila tau models showed that altered CALM levels enhance neurotoxicity by inhibiting autophagy. Functionally, CALM regulates lipid uptake from the plasma membrane to the phagophore and down regulation of CALM disrupts the degradation of tau by autophagy leading to accumulation of tau aggregates.

\section{Friedreich's ataxia}

Friedreich's ataxia is an autosomal recessive neurodegenerative disease caused by decreased expression of frataxin, a mitochondrial protein, leading to mitochondrial dysfunction [174, 175]. However, autopsy reports from patients showed reduced $\mathrm{PE}$, phosphatidylserine and linoleic acid levels in the brain [176]. Moreover, the GAA triplet repeats in frataxin also affect the adjacent gene PIP5KB leading to decreased PI4,5 $\mathrm{P}_{2}$ levels [177]. Although autophagy alterations have been connected to Friedreich's ataxia, the precise molecular mechanism remains enigmatic [178].

\section{Function of sphingolipids in neurodegeneration}

Alterations in sphingolipid metabolism are associated with many neurodegenerative diseases. This is not solely linked to the role of sphingolipids as important components of membranes but also to the bioactivity of some sphingolipids, functioning as cell signalling molecules in a variety of biological processes. Familial forms of neurodegenerative lysosomal storage disorders (LSD) like Gaucher, Krabbe, Niemann-Pick type 1 and Fabry are caused by mutations in genes encoding enzymes that function in the sphingolipid pathway [179-181]. Lysosomes are essential components for the degradation of the autophagosome cargo. Actually, autophagy defects are commonly present in LSDs (review in [182]). This points out the difficulties to segregate pure autophagy defects (e.g. in autophagosome biogenesis or maturation), from lysosomal defects affecting autophagy (e.g. inhibiting the autophagic flux).

It is thought that increased levels of sphingolipids and their byproducts can be neurotoxic [183]. However, the precise molecular mechanisms underlying this neurotoxicity is not well understood. Furthermore, alterations of sphingolipid levels that are not caused by mutations in genes encoding for enzymes of the sphingolipid pathway have also been documented in Alzheimer's, Parkinson's, and multiple sclerosis.

\section{Alteration in SP1 and Cer in neurodegenerative disease}

As early as in the 1960's researchers had established a link between aging and sphingolipid metabolism. Levels of GlcCer increase in the brain with aging and strikingly AD brains show abnormally elevated levels of GlcCer [184]. Years later, research about sphingolipids in aging and $A D$ brains focused more on Cer and S1P. A balance between Cer and S1P, a so-called "Cer/S1P rheostat", defines the equilibrium between the pro- and anti-apoptotic forces in neurons [185-187]. Furthermore, increased levels of S1P in neurons have a neuroprotective function via the induction of autophagy by benzoxazine. This neuroprotective role was neuron specific, since benzoxazine did not induce autophagy in astrocytes [188].

The function of sphingolipids in degradation of aggregateprone proteins

The accumulation of $A \beta$ as aggregate deposits has been linked to decreased autophagic flux in Alzheimer's patients and increasing evidence places autophagic alterations in the centre of $A D$ pathology. Various reports showed that ASM, which negatively regulates autophagy, is upregulated in brains of Alzheimer's patients $[189,190]$ and that $A \beta$ levels correlate with ASM activity [190]. Inhibition of ASM in $A D$ mice lead to reduced $A \beta$ aggregates and improved memory performance. Furthermore, reducing ASM levels in human iPSC-derived neurons from Alzheimer's patients restores autophagic flux via defects in lysosome biogenesis [191].

Dysregulation of glycosphingolipid metabolism has also been reported in PD. Clinically, PD is diagnosed by the onset of motor symptoms including rigidity and tremor. Post mortem, PD is defined by the loss of dopaminergic neurons and the increased appearance of PD prone proteins including full length SNCA, and the C-terminal fragment of APP in the brain compared to wild type mice. As already mentioned, SGPL1 mutant mice show decreased levels of PE that functions as an anchor for LC3 on the phagophore and consequently impairs LC3 lipidation, leading to accumulation of phagophore-like structures and inhibiting autophagosomal maturation. Accordingly, pharmacological or genetic inhibition of SGPL1 blocks autophagy and induces aggregate accumulation while the addition of PE restores autophagic flux and controls levels of APP and SNCA in primary mouse neurons. Not surprisingly, neuron-specific depletion of SGPL1 in mice leads to impairment in memory and learning. These cognitive deficits were observed using a Morris water maze to analyse spatial learning and memory but also in an associative learning and memory test [135]. Moreover, mutations in glucocerebrosidase (GBA) results in increased GlcCer levels in lysosomes, thus affecting the degradation of SNCA by the lysosome [192]. Indeed, the risk of developing PD is increased five-fold even when only one GBA allele is mutated [193]. Work in 
primary neurons has further implicated sphingolipids in SNCA-associated pathology underlying PD. Mutant SNCA levels were reduced in primary neurons treated with a GlcCer synthase inhibitor that led to increased autophagy flux [118].

There is also an intriguing link between Cer accumulation and retromer disruption in Parkinson's fly models for PLA2G6, VPS35 and SNCA [194]. The authors found that PLA2G6 loss of function mutation affects Retromer function via the stability of its subunits; VPS35 and VPS29. This in turn affects retrieval of membrane bound sphingolipids via the endolysosomal system, leading to the accumulation of Cer that enhances further lysosomal dysfunction.

\section{CONCLUSION}

In this review we highlighted the function of lipids in various stages of the autophagy pathway, where they can act as recognition motif to attract regulatory autophagy complexes, to regulate the autophagy core machinery as bioactive lipids or even by regulating transcription of ATGs (Figure 6). Moreover, alterations of the lipid metabolism leads to defects in the autophagy pathway, illustrating the tight connection between lipid supply and the formation/progression of the autophagosome.

Currently available evidence suggests that the accumulation of ubiquitin-positive protein aggregates is a common event in different neurodegenerative diseases like Alzheimer's, Parkinson's, amyotrophic lateral sclerosis, Charcot-Marie-Tooth, Huntington's and Friedrich's ataxia. Autophagy is one of the major pathways that is capable of degrading misfolded proteins and aggregates and therefore autophagic alterations lead to the accumulation of aggregates and there is ample evidence in literature showing that alterations of the autophagy pathway promote neurodegeneration. Not surprisingly, restoring autophagic defects in neurodegenerative disease has gathered special attention as a therapeutic target. On the other side, alterations in lipid metabolism have been connected to neurodegeneration and the accumulation of aggregates. In recent years, mutations in various phosphatases and kinases that target specific Ptdlns have been discovered in amyotrophic lateral sclerosis, Charcot-Marie-Tooth disease, Huntington's and Parkinson's patients. Furthermore, not only alterations in Ptdlns pathway but also in sphingolipid metabolism have been tightly connected to neurodegenerative diseases. For instance, changes in the sphingolipid rheostat are implicated in the most common neurodegenerative diseases Alzheimer's and Parkinson's. Sphingolipid rheostat is defined by the reciprocal role of the lipids Cer and S1P. In this model S1P has a pro-survival role while Cer is thought to play a pro-apoptotic role. The sphingolipid rheostat has not only been discussed in the context of neurodegeneration and physiological homeostatic processes but also in the regulation of autophagy, an essential process in many (patho)physiological events. Besides the importance of sphingolipid rheostat in pathology, homeostasis, and autophagy we are still not certain of the underlying mechanisms of this process. We propose a direct link be- tween dysfunction of lipid metabolism and autophagic alterations that ultimately leads to neurodegeneration. Alterations in autophagy and lipid metabolism have been independently linked to neurodegenerative disease rather than as part of a unique functional network. Alterations of the lipid metabolism have a direct impact on the autophagic pathway and through this could impact neuronal and synaptic function, leading to the accumulation of dysfunctional proteins and aggregates that promote neurodegeneration. Currently, targeting of both the autophagy pathway and especially the sphingolipid pathway are seen as a therapeutic opportunity for various neurodegenerative diseases (reviewed in [195]). However, a much more comprehensive understanding of the interaction of lipids with autophagy is required to elaborate predictive models that would permit evaluation of side effects in neuronal homeostasis over potential benefits. The fact that the lipid composition of the brain changes during ageing, a major risk factor for neurodegenerative diseases, is not new (for review [196]). However, a comprehensive characterization of this lipid changes in a cell-type fashion during the neurodegenerative process is still incomplete. Moreover, we are still missing the full picture of the dynamics of the autophagosomal structures and their lipid composition at a cellular and subcellular (e.g. cell compartments) levels. Emerging techniques like correlative light and electronic microscopy (CLEM) may help to better understand the ultrastructure of autophagosomal structures in a cell and even compartment specific manner. However, the precise identification of the lipid composition of autophagosomal membranes is still a challenge.

Yeast is a valuable organism for autophagy research, however, there are likely differences in the autophagosome lipid composition between yeast and mammals [197]. These differences may be further complicated by the potential differences between the autophagosomes of mammals originating from different organelles. Moreover, the therapeutic regulation of autophagy via the manipulation of the local lipid composition first requires a better understanding of the mechanisms by which autophagy can dictate cell death or survival in neuronal cells. This balance between cell death and survival is a critical issue in neurodegeneration and also in cancer. For instance, the idea of targeting sphingolipid metabolism (such as Cer) as a therapeutic approach has been investigated in cancer research, but progress is limited partially due to an incomplete knowledge of the interplay between Cer and autophagy. There are a few drugs in different clinical trial phases aiming to target the lipid metabolism (for a review see [198, 199]), the development of drugs to specifically modulate autophagy by targeting the $\mathrm{PI}$ and especially the sphingolipid metabolisms is yet a nascent field. An improved understanding of how lipids regulate basal and induced autophagy in healthy individuals and during neurodegenerative conditions will be essential to identify better therapeutic molecules targeting lipid metabolism and autophagy. A pharmacological manipulation of lipid metabolism in neurons and glia may not only be useful for neurodegenerative disorders but for a larger set of neurological condi- 


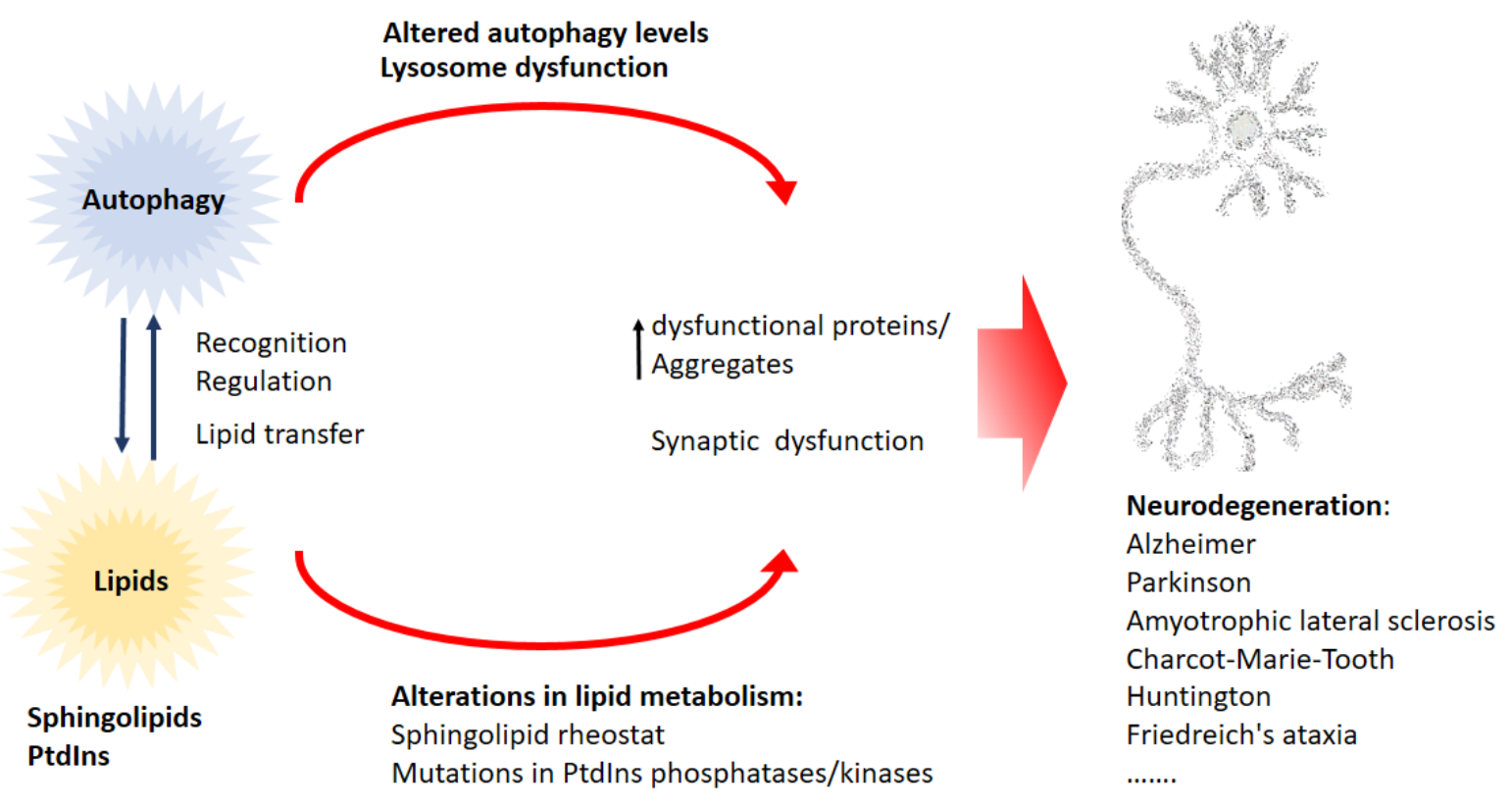

FIGURE 6: Proposed link of lipids in autophagy and neurodegeneration. There is a tight relationship between lipid metabolism and autophagy. Various sphingolipids function as bioactive lipids in the regulation of autophagy, while phosphoinositide phosphates (Ptdlns) mainly function in the recruitment of autophagic factors. Autophagy is known to be an essential physiological mechanism to degrade dysfunctional and aggregate-prone proteins that are commonly accumulated in neurodegenerative disease. Changes in the sphingolipid rheostat (imbalance in the ratio between the concentrations of the apoptosis activator ceramide, and the anti-apoptotic mediator sphingosine-1phosphate) have been implicated in many neurodegenerative diseases. Deregulation of phosphatidylinositol levels lead to neurodegeneration and various phosphatases and kinases targeting phosphatidylinositols have been found to be mutated in various neurodegenerative diseases.

tions. For instance, a possible role for autophagy [200] and lipid alterations [201] has been identified in animal models of DYT1 primary dystonia.

Advances in the field are right now limited by the current means to intervene in lipid pathways and in the detection of specific lipid species in vivo. Technological advances like novel lipid probes and microscopy techniques to visualize and study lipids in vivo will be useful to overcome these limitations.

\section{ACKNOWLEDGMENTS}

Research in the laboratory is supported by the Initiative d'excellence de I'Université de Bordeaux (IDEX) and the Region Nouvelle-Aquitaine. We thank Patrick Main for proof reading of the manuscript.

\section{CONFLICT OF INTEREST}

The authors declare no conflict of interest.

\section{COPYRIGHT}

(C) 2020 Hernandez-Diaz and Soukup. This is an open-access article released under the terms of the Creative Commons Attribution (CC BY) license, which allows the unrestricted use, distribution, and reproduction in any medium, provided the original author and source are acknowledged.

Please cite this article as: Sergio Hernandez-Diaz and SandraFausia Soukup (2020). The role of lipids in autophagy and its implication in neurodegeneration. Cell Stress 4(7): 167-186. doi: 10.15698/cst2020.07.225

\section{REFERENCES}

1. Bach J-P, Ziegler U, Deuschl G, Dodel R, and Doblhammer-Reiter G (2011). Projected numbers of people with movement disorders in the years 2030 and 2050. Mov Disord 26(12): 2286-2290. doi: $10.1002 / \mathrm{mds} .23878$

2. Dorsey ER, Constantinescu R, Thompson JP, Biglan KM, Holloway RG Kieburtz K, Marshall FJ, Ravina BM, Schifitto G, Siderowf A, and Tanner CM (2007). Projected number of people with Parkinson disease in the most populous nations, 2005 through 2030. Neurology 68:384-386. doi: 10.1212/01.wnl.0000271777.50910.73
3. Mayeux R, and Stern Y (2012). Epidemiology of Alzheimer disease. Cold Spring Harb Perspect Med 2(8): a006239. doi: 10.1101/cshperspect.a006239

4. Spillantini MG, Schmidt ML, Lee VM-Y, Trojanowski JQ, Jakes R, and Goedert M (1997). $\alpha$-Synuclein in Lewy bodies. Nature 388(6645): 839-840. doi: 10.1038/42166

5. Zhu X, Siedlak SL, Smith MA, Perry G, and Chen SG (2006). LRRK2 protein is a component of lewy bodies. Ann Neurol 60(5): 617-618. doi: 10.1002/ana.20928 
6. De Strooper B, and Karran E (2016). The Cellular Phase of Alzheimer's Disease. Cell 164(4): 603-615. doi: 10.1016/j.cell.2015.12.056

7. Selkoe DJ (2002). Alzheimer's disease is a synaptic failure. Science 298: 789-791. doi: 10.1126/science.1074069

8. Kim HJ et al. (2013). Mutations in prion-like domains in hnRNPA2B1 and hnRNPA1 cause multisystem proteinopathy and ALS. Nature 495(7442): 467-473. doi: 10.1038/nature11922

9. Mangiarini L (1996). Exon 1 of the HD gene with an expanded CAG repeat is sufficient to cause a progressive neurological phenotype in transgenic mice. Cell 87: 493-506. doi: 10.1016/s00928674(00)81369-0

10. Nitsch RM, Blusztajn JK, Pittas AG, Slack BE, Growdon JH, and Wurtman RJ (1992). Evidence for a membrane defect in Alzheimer disease brain. Proc Natl Acad Sci U S A 89(5): 1671-1675. doi: 10.1073/pnas.89.5.1671

11. Cutler RG, Kelly J, Storie K, Pedersen WA, Tammara A, Hatanpaa K, Troncoso JC, and Mattson MP (2004). Involvement of oxidative stressinduced abnormalities in ceramide and cholesterol metabolism in brain aging and Alzheimer's disease. Proc Natl Acad Sci U S A 101(7): 2070-2075. doi: 10.1073/pnas.0305799101

12. Imberdis $T$, Negri J, Ramalingam $N$, Terry-Kantor $E$, Ho GPH, Fanning S, Stirtz G, Kim T-E, Levy OA, Young-Pearse TL, Selkoe D, and Dettmer U (2019). Cell models of lipid-rich alpha-synuclein aggregation validate known modifiers of alpha-synuclein biology and identify stearoyl-CoA desaturase. Proc Natl Acad Sci U S A 116(41): 20760-20769. doi: 10.1073/pnas.1903216116

13. Isacson O, Brekk OR, and Hallett PJ (2019). Novel Results and Concepts Emerging From Lipid Cell Biology Relevant to Degenerative Brain Aging and Disease. Front Neurol 10: 1053 . doi: 10.3389/fneur.2019.01053

14. Shahmoradian SH et al. (2019). Lewy pathology in Parkinson's disease consists of crowded organelles and lipid membranes. Nat Neurosci 22(7): 1099-1109. doi: 10.1038/s41593-019-0423-2

15. Grassi S, Giussani P, Mauri L, Prioni S, Sonnino S, and Prinetti A (2019). LIPID RAFTS AND NEURODEGENERATION: Structural and functional roles in physiologic aging and neurodegenerative diseases. J Lipid Res 61(5):636-654. doi: 10.1194/jlr.TR119000427

16. Hol EM, and Scheper W (2008). Protein Quality Control in Neurodegeneration: Walking the Tight Rope Between Health and Disease. J Mol Neurosci 34(1): 23-33. doi: 10.1007/s12031-007-00138

17. Waelter S, Boeddrich A, Lurz R, Scherzinger E, Lueder G, Lehrach $H$, and Wanker EE (2001). Accumulation of mutant huntingtin fragments in aggresome-like inclusion bodies as a result of insufficient protein degradation. Mol Biol Cell 12(5): 1393-1407. doi: 10.1091/mbc.12.5.1393

18. Winslow AR, Chen C-W, Corrochano S, Acevedo-Arozena A, Gordon DE, Peden A a, Lichtenberg M, Menzies FM, Ravikumar B, Imarisio S, Brown S, O'Kane CJ, and Rubinsztein DC (2010). $\alpha$-Synuclein impairs macroautophagy: implications for Parkinson's disease. J Cell Biol 190(6): 1023-37. doi: 10.1083/jcb.201003122

19. Komatsu M, Waguri S, Chiba T, Murata S, Iwata J, Tanida I, Ueno T, Koike M, Uchiyama $Y$, Kominami E, and Tanaka K (2006). Loss of autophagy in the central nervous system causes neurodegeneration in mice. Nature 441(7095): 880-884. doi: 10.1038/nature04723

20. Friedman LG, Lachenmayer ML, Wang J, He L, Poulose SM, Komatsu M, Holstein GR, and Yue Z (2012). Disrupted autophagy leads to dopaminergic axon and dendrite degeneration and promotes presynaptic accumulation of $\alpha$-synuclein and LRRK2 in the brain. J Neurosci 32(22): 7585-93. doi: 10.1523/JNEUROSCI.5809-11.2012
21. Yao T-P (2010). The role of ubiquitin in autophagy-dependent protein aggregate processing. Genes Cancer 1(7): 779-786. doi: $10.1177 / 1947601910383277$

22. Saito $T$, Kuma $A$, Sugiura $Y$, Ichimura $Y$, Obata $M$, Kitamura $H$, Okuda S, Lee H-C, Ikeda K, Kanegae Y, Saito I, Auwerx J, Motohashi H, Suematsu M, Soga T, Yokomizo T, Waguri S, Mizushima N, and Komatsu M (2019). Autophagy regulates lipid metabolism through selective turnover of NCoR1. Nat Commun 10(1): 1567. doi: 10.1038/s41467-019-08829-3

23. Singh $R$, Kaushik $S$, Wang $Y$, Xiang $Y$, Novak I, Komatsu $M$, Tanaka $K$, Cuervo AM, and Czaja MJ (2009). Autophagy regulates lipid metabolism. Nature 458(7242): 1131-1135. doi: 10.1038/nature07976

24. Shpilka T, Welter E, Borovsky N, Amar N, Mari M, Reggiori F, and Elazar Z (2015). Lipid droplets and their component triglycerides and steryl esters regulate autophagosome biogenesis. EMBO J 34(16): 2117-2131. doi: 10.15252/embj.201490315

25. Vicinanza M, Korolchuk VI, Ashkenazi A, Puri C, Menzies FM, Clarke $\mathrm{JH}$, and Rubinsztein DC (2015). PI(5)P Regulates Autophagosome Biogenesis. Mol Cell 3(5): 1-16. doi: 10.1016/j.molcel.2014.12.007

26. Baskaran S, Ragusa MJ, Boura E, and Hurley JH (2012). Two-Site Recognition of Phosphatidylinositol 3-Phosphate by PROPPINs in Autophagy. Mol Cell 47(3): 339-348. doi: 10.1016/j.molcel.2012.05.027

27. Li $X$, Wang $X$, Zhang $X$, Zhao $M$, Tsang WL, Zhang $Y$, Yau RGW, Weisman LS, and Xu $\mathrm{H}$ (2013). Genetically encoded fluorescent probe to visualize intracellular phosphatidylinositol 3,5-bisphosphate localization and dynamics. Proc Natl Acad Sci U S A 110(52): 2116521170. doi: 10.1073/pnas. 1311864110

28. Gaullier J-M, Simonsen A, D'Arrigo A, Bremnes B, Stenmark $H$, and Aasland R (1998). FYVE fingers bind Ptdlns(3)P. Nature 394(6692): 432-433. doi: 10.1038/28767

29. Cremona O, Di Paolo G, Wenk MR, Luthi A, Kim WT, Takei K, Daniell L, Nemoto Y, Shears SB, Flavell RA, McCormick DA, and De Camilli $P$ (1999). Essential role of phosphoinositide metabolism in synaptic vesicle recycling. Cell 99(6): 1041-1052. doi: 10.1016/S00928674(00)81649-9

30. Tsukada M, and Ohsumi $Y$ (1993). Isolation and characterization of autophagy-defective mutants of Saccharomyces cerevisiae. FEBS Lett 333(1-2): 169-174. doi: 10.1016/0014-5793(93)80398-e

31. Mortimore GE, and Schworer CM (1977). Induction of autophagy by amino-acid deprivation in perfused rat liver. Nature 270(5633): 174-176. doi: 10.1038/270174a0

32. Uttenweiler A, and Mayer A (2008). Microautophagy in the yeast Saccharomyces cerevisiae. Methods Mol Biol 445: 245-259. doi: 10.1007/978-1-59745-157-4_16

33. Sahu R, Kaushik S, Clement CC, Cannizzo ES, Scharf B, Follenzi A, Potolicchio I, Nieves E, Cuervo AM, and Santambrogio L (2011). Microautophagy of Cytosolic Proteins by Late Endosomes. Dev Cell 20(1): 131-139. doi: 10.1016/j.devcel.2010.12.003

34. Kiffin R, Christian C, Knecht E, and Cuervo AM (2004). Activation of chaperone-mediated autophagy during oxidative stress. Mol Biol Cell 15(11): 4829-4840. doi: 10.1091/mbc.e04-06-0477

35. Liang C-C, Wang C, Peng X, Gan B, and Guan J-L (2010). Neuralspecific deletion of FIP200 leads to cerebellar degeneration caused by increased neuronal death and axon degeneration. J Biol Chem 285(5): 3499-509. doi: 10.1074/jbc.M109.072389

36. Dice JF (1990). Peptide sequences that target cytosolic proteins for Iysosomal proteolysis. Trends Biochem Sci 15(8): 305-309. doi: 10.1016/0968-0004(90)90019-8 
37. Axe EL, Walker $S$ a., Manifava $M$, Chandra $P$, Roderick $H L$, Habermann A, Griffiths G, and Ktistakis NT (2008). Autophagosome formation from membrane compartments enriched in phosphatidylinositol 3-phosphate and dynamically connected to the endoplasmic reticulum. J Cell Biol 182(4): 685-701. doi: 10.1083/jcb.200803137

38. Stromhaug PE, and Seglen PO (1993). Evidence for acidity of prelysosomal autophagic/endocytic vacuoles (amphisomes). Biochem J 291 (Pt 1): 115-121. doi: 10.1042/bj2910115

39. Fader CM, Sánchez D, Furlán M, and Colombo MI (2008). Induction of autophagy promotes fusion of multivesicular bodies with autophagic vacuoles in K562 cells. Traffic 9(2): 230-250. doi: 10.1111/j.1600-0854.2007.00677.x

40. Jäger S, Bucci C, Tanida I, Ueno $T$, Kominami E, Saftig $P$, and Eskelinen E-L (2004). Role for Rab7 in maturation of late autophagic vacuoles. J Cell Sci 117(Pt 20): 4837-4848. doi: 10.1242/jcs.01370

41. Settembre C, Di Malta C, Polito VA, Arencibia MG, Vetrini F, Erdin SU, Erdin SU, Huynh T, Medina D, Colella P, Sardiello M, Rubinsztein DC, and Ballabio A (2011). TFEB Links Autophagy to Lysosomal Biogenesis. Science 332(6036): 1429-1433. doi: 10.1126/science. 1204592

42. DE DUVE C (1963). The lysosome. Sci Am 208: 64-72. doi: 10.1038/scientificamerican0563-64

43. Mari $M$, Tooze $S$, and Reggiori $F$ (2011). The puzzling origin of the autophagosomal membrane. F1000 Biol Rep 3:25. doi: 10.3410/B3-25.

44. Lamb C a, Yoshimori T, and Tooze S a (2013). The autophagosome: origins unknown, biogenesis complex. Nat Rev Mol Cell Biol 14(12): 759-74. doi: 10.1038/nrm3696

45. Galluzzi L et al. (2017). Molecular definitions of autophagy and related processes. EMBO J 36(13): 1811-1836. doi: 10.15252/embj.201796697

46. Rubinsztein DC, Shpilka T, and Elazar Z (2012). Mechanisms of autophagosome biogenesis. Curr Biol 22(1): R29-34. doi: 10.1016/j.cub.2011.11.034

47. Abada A, and Elazar Z (2014). Getting ready for building: signaling and autophagosome biogenesis. EMBO Rep 15(8): 839-852. doi: 10.15252/embr.201439076

48. Mercer TJ, Gubas A, and Tooze XSA (2018). A molecular perspective of mammalian autophagosome biogenesis. J Biol Chem 1 5386-5395. doi: 10.1074/jbc.R117.810366

49. Cremona O, Di Paolo G, Wenk MR, Lüthi A, Kim WT, Takei K Daniell L, Nemoto Y, Shears SB, Flavell R a, McCormick D a, and De Camilli $P$ (1999). Essential role of phosphoinositide metabolism in synaptic vesicle recycling. Cell 99(2): 179-88. doi: 10.1016/S00928674(00)81649-9

50. Wallroth $A$, and Haucke $V$ (2018). Phosphoinositide conversion in endocytosis and the endolysosomal system. J Biol Chem 293(5): 1526-1535. doi: 10.1074/jbc.R117.000629

51. Wucherpfennig T, Wilsch-Bräuninger $M$, and González-Gaitán M (2003). Role of Drosophila Rab5 during endosomal trafficking at the synapse and evoked neurotransmitter release. J Cell Biol 161(3): 609624. doi: $10.1083 / j c b .200211087$

52. de Renzis S, Sönnichsen B, and Zerial M (2002). Divalent Rab effectors regulate the sub-compartmental organization and sorting of early endosomes. Nat Cell Biol 4(2): 124-133. doi: 10.1038/ncb744

53. Nagy $P$, Kárpáti $M$, Varga $A$, Pircs $K$, Venkei Z, Takáts $S$, Varga $K$, Erdi B, Hegedűs K, and Juhász G (2014). Atg17/FIP200 localizes to perilysosomal Ref(2)P aggregates and promotes autophagy by activation of Atg1 in Drosophila. Autophagy 10(3): 453-67. doi: 10.4161/auto. 27442
54. Sekito T, Kawamata T, Ichikawa R, Suzuki K, and Ohsumi Y (2009). Atg17 recruits Atg9 to organize the pre-autophagosomal structure. Genes Cells 14(5): 525-38. doi: 10.1111/j.1365-2443.2009.01299.x

55. Russell RC, Tian Y, Yuan H, Park HW, Chang Y-Y, Kim J, Kim H, Neufeld TP, Dillin A, and Guan K-L (2013). ULK1 induces autophagy by phosphorylating Beclin-1 and activating VPS34 lipid kinase. Nat Cell Biol 15(7): 741-50. doi: 10.1038/ncb2757

56. Matsunaga K, Morita E, Saitoh T, Akira S, Ktistakis NT, Izumi T, Noda $T$, and Yoshimori $T$ (2010). Autophagy requires endoplasmic reticulum targeting of the PI3-kinase complex via Atg14L. J Cell Biol 190(4): 511-521. doi: 10.1083/jcb.200911141

57. Noda T, Matsunaga K, Taguchi-Atarashi N, and Yoshimori T (2010). Regulation of membrane biogenesis in autophagy via PI3P dynamics. Semin Cell Dev Biol 21(7): 671-676. doi: 10.1016/j.semcdb.2010.04.002

58. Juhász G, Hill JH, Yan Y, Sass M, Baehrecke EH, Backer JM, and Neufeld TP (2008). The class III PI(3)K Vps34 promotes autophagy and endocytosis but not TOR signaling in Drosophila. J Cell Biol 181(4): 655-66. doi: 10.1083/jcb.200712051

59. Lystad $A H$, and Simonsen A (2016). Phosphoinositide-binding proteins in autophagy. FEBS Lett 590(15): 2454-2468. doi: 10.1002/1873-3468.12286

60. Polson HEJ, de Lartigue J, Rigden DJ, Reedijk M, Urbe S, Clague MJ, and Tooze SA (2010). Mammalian Atg18 (WIPI2) localizes to omegasome-anchored phagophores and positively regulates LC3 lipidation. Autophagy 6(4): 506-522. doi: 10.4161/auto.6.4.11863

61. Rieter E, Rieter E, Vinke F, Vinke F, Bakula D, Bakula D, Cebollero E, Cebollero E, Ungermann C, Ungermann C, Proikas-Cezanne T, ProikasCezanne T, Reggiori F, and Reggiori F (2013). Atg18 function in autophagy is regulated by specific sites within its $\beta$-propeller. J Cell Sci 126(Pt 2): 593-604. doi: 10.1242/jcs.115725

62. Proikas-Cezanne T, Takacs Z, Dönnes P, and Kohlbacher O (2015) WIPI proteins: essential PtdIns3P effectors at the nascent autophagosome. J Cell Sci 128(2): 207-17. doi: 10.1242/jcs.146258

63. Kumar $N$, Leonzino $M$, Hancock-Cerutti $W$, Horenkamp FA, Li $P$, Lees JA, Wheeler H, Reinisch KM, and De Camilli P (2018). VPS13A and VPS13C are lipid transport proteins differentially localized at ER contact sites. J Cell Biol 217(10): 3625-3639. doi: $10.1083 /$ jcb. 201807019

64. Valverde DP, Yu S, Boggavarapu V, Kumar N, Lees JA, Walz T, Reinisch KM, and Melia TJ (2019). ATG2 transports lipids to promote autophagosome biogenesis. J Cell Biol 218(6): 1787-1798. doi: 10.1083/jcb.201811139

65. Osawa T, Kotani T, Kawaoka T, Hirata E, Suzuki K, Nakatogawa $\mathrm{H}_{\text {, }}$ Ohsumi $Y$, and Noda NN (2019). Atg2 mediates direct lipid transfer between membranes for autophagosome formation. Nat Struct Mol Biol 26(4): 281-288. doi: 10.1038/s41594-019-0203-4

66. Maeda S, Otomo C, and Otomo T (2019). The autophagic membrane tether ATG2A transfers lipids between membranes. Elife 8: 1-24. doi: $10.7554 /$ eLife. 45777

67. Bozic $M$, van den Bekerom L, Milne BA, Goodman N, Roberston L, Prescott AR, Macartney TJ, Dawe N, and McEwan DG (2020). A conserved ATG2-GABARAP family interaction is critical for phagophore formation. EMBO Rep 21(3): e48412. doi: 10.15252/embr.201948412

68. Dudley LJ, Cabodevilla AG, Makar AN, Sztacho M, Michelberger T, Marsh JA, Houston DR, Martens S, Jiang X, and Gammoh N (2019). Intrinsic lipid binding activity of ATG $16 \mathrm{~L} 1$ supports efficient membrane anchoring and autophagy. EMBO J 38(9): 1-16. doi: 10.15252/embj.2018100554

69. Lystad AH, Carlsson SR, de la Ballina LR, Kauffman KJ, Nag S, 
Yoshimori T, Melia TJ, and Simonsen A (2019). Distinct functions of ATG16L1 isoforms in membrane binding and LC3B lipidation in autophagy-related processes. Nat Cell Biol 21(3): 372-383. doi: 10.1038/s41556-019-0274-9

70. Ichimura $Y$, Kirisako T, Takao T, Satomi Y, Shimonishi $Y$, Ishihara N, Mizushima N, Tanida I, Kominami E, Ohsumi M, Noda T, and Ohsumi Y (2000). A ubiquitin-like system mediates protein lipidation. Nature 408(6811): 488-492. doi: 10.1038/35044114

71. Sakoh-Nakatogawa M, Matoba K, Asai E, Kirisako H, Ishii J, Noda NN, Inagaki F, Nakatogawa $H$, and Ohsumi Y (2013). Atg12-Atg5 conjugate enhances E2 activity of Atg 3 by rearranging its catalytic site. Nat Struct Mol Biol 20(4): 433-439. doi: 10.1038/nsmb.2527

72. Weidberg H, Shvets E, Shpilka T, Shimron F, Shinder V, and Elazar Z (2010). LC3 and GATE-16/GABARAP subfamilies are both essential yet act differently in autophagosome biogenesis. EMBO J 29(11): 17921802. doi: $10.1038 /$ emboj.2010.74

73. Hanada T, Noda NN, Satomi Y, Ichimura Y, Fujioka Y, Takao T, Inagaki F, and Ohsumi Y (2007). The Atg12-Atg5 conjugate has a novel E3-like activity for protein lipidation in autophagy. J Biol Chem 282(52): 37298-37302. doi: 10.1074/jbc.C700195200

74. Fan W, Nassiri A, and Zhong Q (2011). Autophagosome targeting and membrane curvature sensing by Barkor/Atg14(L). Proc Natl Acad Sci 108(19): 7769-7774. doi: 10.1073/pnas.1016472108

75. Nath S, Dancourt J, Shteyn V, Puente G, Fong WM, Nag S, Bewersdorf J, Yamamoto A, Antonny B, and Melia TJ (2014). Lipidation of the LC3/GABARAP family of autophagy proteins relies on a membrane-curvature-sensing domain in Atg3. Nat Cell Biol 16(5): 415-424. doi: 10.1038/ncb2940

76. Ragusa MJ, Stanley RE, Hurley JH, and Michael J. Ragusa, Robin E. Stanley and JHH (2012). Architecture of the Atg17 Complex as a Scaffold for Autophagosome Biogenesis. Cell 151(7): 1501-1512. doi: 10.1016/j.cell.2012.11.028.Architecture

77. Nguyen N, Shteyn V, and Melia TJ (2017). Sensing Membrane Curvature in Macroautophagy. J Mol Biol 429(4): 457-472. doi: 10.1016/j.jmb.2017.01.006

78. Ringstad N, Nemoto $Y$, and De Camilli $P$ (2001). Differential Expression of Endophilin 1 and 2 Dimers at Central Nervous System Synapses. J Biol Chem 276(44): 40424-40430. doi: 10.1074/jbc.M106338200

79. Farsad K, Ringstad N, Takei K, Floyd SR, Rose K, and De Camilli P (2001). Generation of high curvature membranes mediated by direct endophilin bilayer interactions. J Cell Biol 155(2): 193-200. doi: 10.1083/jcb.200107075

80. Milosevic I, Giovedi S, Lou X, Raimondi A, Collesi C, Shen $H_{\text {, }}$ Paradise S, O'Toole E, Ferguson S, Cremona O, and De Camilli P (2011). Recruitment of endophilin to clathrin-coated pit necks is required for efficient vesicle uncoating after fission. Neuron 72(4): 587-601. doi: 10.1016/j.neuron.2011.08.029

81. Verstreken $P$, Kjaerulff $\mathrm{O}$, Lloyd TE, Atkinson R, Zhou $\mathrm{Y}$, Meinertzhagen I a., and Bellen HJ (2002). Endophilin Mutations Block Clathrin-Mediated Endocytosis but Not Neurotransmitter Release. Cell 109(1): 101-112. doi: 10.1016/S0092-8674(02)00688-8

82. Soukup S-F, Kuenen $S$, Vanhauwaert $R$, Manetsberger J, Hernández-Díaz S, Swerts J, Schoovaerts N, Vilain S, Gounko N V., Vints K, Geens A, De Strooper B, and Verstreken P (2016). A LRRK2Dependent EndophilinA Phosphoswitch Is Critical for Macroautophagy at Presynaptic Terminals. Neuron 92(4): 829-844. doi: 10.1016/j.neuron.2016.09.037

83. Arranz AM, Delbroek L, Van Kolen K, Guimarães MR, Mandemakers W, Daneels G, Matta S, Calafate S, Shaban H, Baatsen P, De Bock P-J, Gevaert K, Vanden Berghe P, Verstreken P, De Strooper B, and Moechars D (2015). LRRK2 functions in synaptic vesicle endocytosis through a kinase-dependent mechanism. J Cell Sci 128(3) 541-552. doi: 10.1242/jcs.158196

84. Ambroso MR, Hegde BG, and Langen R (2014). Endophilin A1 induces different membrane shapes using a conformational switch that is regulated by phosphorylation. Proc Natl Acad Sci U S A 111: 6982-7. doi: 10.1073/pnas.1402233111

85. Fruman DA, Chiu H, Hopkins BD, Bagrodia S, Cantley LC, and Abraham RT (2017). The PI3K Pathway in Human Disease. Cell 170(4): 605-635. doi: 10.1016/j.cell.2017.07.029

86. Ueno $T$, Sato $W$, Horie $Y$, Komatsu M, Tanida I, Yoshida $M$, Ohshima S, Mak TW, Watanabe S, and Kominami E (2008). Loss of Pten, a tumor suppressor, causes the strong inhibition of autophagy without affecting LC3 lipidation. Autophagy 4(5): 692-700. doi: 10.4161/auto.6085

87. Melani M, Valko A, Romero NM, Aguilera MO, Acevedo JM, Bhujabal Z, Perez-Perri J, de la Riva-Carrasco R V, Katz MJ, Sorianello E, D'Alessio C, Juhasz G, Johansen T, Colombo MI, and Wappner P (2017). Zonda is a novel early component of the autophagy pathway in Drosophila. Mol Biol Cell 28(22): 3070-3081. doi: 10.1091/mbc.E1611-0767

88. Hegedus K, Takats S, Boda A, Jipa A, Nagy P, Varga K, Kovacs AL, and Juhasz $G$ (2016). The Ccz1-Mon1-Rab7 module and Rab5 control distinct steps of autophagy. Mol Biol Cell 27(20): 3132-3142. doi: 10.1091/mbc.E16-03-0205

89. Hasegawa J, Iwamoto R, Otomo T, Nezu A, Hamasaki $M$, and Yoshimori T (2016). Autophagosome-lysosome fusion in neurons requires INPP 5E, a protein associated with Joubert syndrome . EMBO J 35(17): 1853-1867. doi: 10.15252/embj.201593148

90. Pankiv S, Alemu EA, Brech A, Bruun J-A, Lamark T, Overvatn A, Bjorkoy G, and Johansen T (2010). FYCO1 is a Rab7 effector that binds to LC3 and PI3P to mediate microtubule plus end-directed vesicle transport. J Cell Biol 188(2): 253-269. doi: 10.1083/jcb.200907015

91. Mrakovic A, Kay JG, Furuya W, Brumell JH, and Botelho RJ (2012). Rab7 and Arl8 GTPases are necessary for lysosome tubulation in macrophages. Traffic 13(12): 1667-1679. doi: 10.1111/tra.12003

92. Sim J, Osborne KA, Argudo Garcia I, Matysik AS, and Kraut R (2019). The BEACH Domain Is Critical for Blue Cheese Function in a Spatial and Epistatic Autophagy Hierarchy. Front cell Dev Biol 7: 129. doi: 10.3389/fcell.2019.00129

93. Judith D, Jefferies HBJ, Boeing S, Frith D, Snijders AP, and Tooze SA (2019). ATG9A shapes the forming autophagosome through Arfaptin 2 and phosphatidylinositol 4-kinase Illbeta. J Cell Biol 218(5): 16341652. doi: $10.1083 / j c b .201901115$

94. Cebollero E, Van Der Vaart A, Zhao M, Rieter E, Klionsky DJ, Helms $J B$, and Reggiori F (2012). Phosphatidylinositol-3-phosphate clearance plays a key role in autophagosome completion. Curr Biol 22(17): 1545-1553. doi: 10.1016/j.cub.2012.06.029

95. Fetalvero KM, Yu Y, Goetschkes M, Liang G, Valdez RA, Gould T, Triantafellow E, Bergling S, Loureiro J, Eash J, Lin V, Porter JA, Finan PM, Walsh K, Yang Y, Mao X, and Murphy LO (2013). Defective autophagy and mTORC1 signaling in myotubularin null mice. Mol Cell Biol 33(1): 98-110. doi: 10.1128/MCB.01075-12

96. Vergne I, Roberts E, Elmaoued RA, Tosch V, Delgado MA, ProikasCezanne T, Laporte J, and Deretic V (2009). Control of autophagy initiation by phosphoinositide 3-phosphatase Jumpy. EMBO J 28(15): 2244-2258. doi: 10.1038/emboj.2009.159

97. Taguchi-Atarashi N, Hamasaki M, Matsunaga K, Omori H, Ktistakis NT, Yoshimori T, and Noda T (2010). Modulation of local Ptdlns3P levels by the PI phosphatase MTMR3 regulates constitutive autophagy. Traffic 11(4): 468-478. doi: 10.1111/j.1600-0854.2010.01034.x 
98. Zou J, Zhang C, Marjanovic J, Kisseleva M V, Majerus PW, and Wilson MP (2012). Myotubularin-related protein (MTMR) 9 determines the enzymatic activity, substrate specificity, and role in autophagy of MTMR8. Proc Natl Acad Sci U S A 109(24): 9539-9544. doi: 10.1073/pnas.1207021109

99. Harris TW, Hartwieg E, Horvitz HR, and Jorgensen EM (2000). Mutations in synaptojanin disrupt synaptic vesicle recycling. J Cell Biol 150(3): 589-600. doi: 10.1083/jcb.150.3.589

100. McPherson PS, Garcia EP, Slepnev VI, David C, Zhang X, Grabs D, Sossin WS, Bauerfeind R, Nemoto $Y$, and De Camilli P (1996). A presynaptic inositol-5-phosphatase. Nature 379(6563): 353-7. doi: 10.1038/379353a0

101. Verstreken P, Koh T-W, Schulze KL, Zhai RG, Hiesinger PR, Zhou Y, Mehta SQ, Cao Y, Roos J, and Bellen HJ (2003). Synaptojanin Is Recruited by Endophilin to Promote Synaptic Vesicle Uncoating. Neuron 40(4): 733-748. doi: 10.1016/S0896-6273(03)00644-5

102. Vanhauwaert R, Kuenen S, Masius R, Bademosi A, Manetsberger J Schoovaerts N, Bounti L, Gontcharenko S, Swerts J, Vilain S, Picillo M, Barone P, Munshi ST, de Vrij FM, Kushner SA, Gounko N V, Mandemakers W, Bonifati V, Meunier FA, Soukup S, and Verstreken P (2017). The SAC1 domain in synaptojanin is required for autophagosome maturation at presynaptic terminals. EMBO J 36(10): 1392-1411. doi: 10.15252/embj.201695773

103. Whisstock JC, Wiradjaja F, Waters JE, and Gurung R (2002). The structure and function of catalytic domains within inositol polyphosphate 5-phosphatases. IUBMB Life 53(1): 15-23. doi: 10.1080/15216540210814

104. Tsujishita Y, Guo S, Stolz LE, York JD, and Hurley JH (2001). Specificity determinants in phosphoinositide dephosphorylation: crystal structure of an archetypal inositol polyphosphate 5phosphatase. Cell 105(3): 379-89. doi: 10.1016/S00928674(01)00326-9

105. Guo S, Stolz LE, Lemrow SM, and York JD (1999). SAC1-like Domains of Yeast SAC1,INP52, and INP53 and of Human Synaptojanin Encode Polyphosphoinositide Phosphatases. J Biol Chem 274(19): 12990-12995. doi: 10.1074/jbc.274.19.12990

106. Krebs CE, Karkheiran S, Powell JC, Cao M, Makarov V, Darvish H, Di Paolo G, Walker RH, Shahidi GA, Buxbaum JD, De Camilli P, Yue Z, and Paisán-Ruiz C (2013). The Sac1 domain of SYNJ1 identified mutated in a family with early-onset progressive parkinsonism with generalized seizures. Hum Mutat 34(9): 1200-1207. doi: 10.1002/humu.22372

107. Olgiati S, De Rosa A, Quadri M, Criscuolo C, Breedveld G, Picillo M Pappatà S, Quarantelli M, Barone P, De Michele G, and Bonifati V (2014). PARK20 caused by SYNJ1 homozygous Arg258GIn mutation in a new Italian family. Neurogenetics 15(3): 183-188. doi: 10.1007/s10048-014-0406-0

108. Quadri M, Fang M, Picillo M, Olgiati S, Breedveld GJ, Graafland J, Wu B, Xu F, Erro R, Amboni M, Pappatà S, Quarantelli M, Annesi G, Quattrone A, Chien HF, Barbosa ER, Oostra B a, Barone P, Wang J, Bonifati V, Network TIPG, Oostra B a, Barone P, Wang J, and Bonifati V (2013). Mutation in the SYNJ1 gene associated with autosomal recessive, early-onset Parkinsonism. Hum Mutat 34(9): 1208-15. doi: 10.1002/humu.22373

109. Sun $T$, Wang $X$, Lu $Q$, Ren $H$, and Zhang $H$ (2011). CUP-5, the $C$. elegans ortholog of the mammalian lysosomal channel protein MLN1/TRPML1, is required for proteolytic degradation in autolysosomes. Autophagy 7(11): 1308-1315. doi: 10.4161/auto.7.11.17759

110. Feng $X$, Huang $Y$, Lu Y, Xiong J, Wong C-O, Yang P, Xia J, Chen D, Du G, Venkatachalam K, Xia X, and Zhu MX (2014). Drosophila TRPML forms $\mathrm{PI}(3,5) \mathrm{P} 2$-activated cation channels in both endolysosomes and plasma membrane. J Biol Chem 289(7): 4262-4272. doi: 10.1074/jbc.M113.506501

111. Zhang X, Cheng X, Yu L, Yang J, Calvo R, Patnaik S, Hu X, Gao Q, Yang M, Lawas M, Delling M, Marugan J, Ferrer M, and Xu H (2016). MCOLN1 is a ROS sensor in lysosomes that regulates autophagy. Nat Commun 7: 12109. doi: 10.1038/ncomms12109

112. Wang W, Gao Q, Yang M, Zhang X, Yu L, Lawas M, Li X, BryantGenevier M, Southall NT, Marugan J, Ferrer M, and Xu H (2015). Upregulation of lysosomal TRPML1 channels is essential for lysosomal adaptation to nutrient starvation. Proc Natl Acad Sci U S A 112(11): E1373-81. doi: 10.1073/pnas.1419669112

113. Wang $H$, Sun $H Q$, Zhu $X$, Zhang L, Albanesi J, Levine B, and Yin $H$ (2015). GABARAPs regulate PI4P-dependent autophagosome: Lysosome fusion. Proc Natl Acad Sci U S A 112(22): 7015-7020. doi: 10.1073/pnas.1507263112

114. Baba T, Toth DJ, Sengupta N, Kim YJ, and Balla T (2019). Phosphatidylinositol 4,5-bisphosphate controls Rab7 and PLEKHM1 membrane cycling during autophagosome-lysosome fusion. EMBO J 38(8): e100312. doi: 10.15252/embj.2018100312

115. Hannun YA, and Obeid LM (2018). Sphingolipids and their metabolism in physiology and disease. Nat Rev Mol Cell Biol 19(3): 175-191. doi: 10.1038/nrm.2017.107

116. Guenther GG, Peralta ER, Rosales KR, Wong SY, Siskind L, and Edinger AL (2008). Ceramide starves cells to death by downregulating nutrient transporter proteins. Proc Natl Acad Sci U S A 105(45): 17402-17407. doi: 10.1073/pnas.0802781105

117. Scarlatti F, Bauvy C, Ventruti A, Sala G, Cluzeaud F, Vandewalle A, Ghidoni R, and Codogno $P$ (2004). Ceramide-mediated Macroautophagy Involves Inhibition of Protein Kinase B and Upregulation of Beclin 1. J Biol Chem 279(18): 18384-18391. doi: 10.1074/jbc.M313561200

118. Shen W, Henry AG, Paumier KL, Li L, Mou K, Dunlop J, Berger Z, and Hirst WD (2014). Inhibition of glucosylceramide synthase stimulates autophagy flux in neurons. J Neurochem 129(5): 884-894. doi: 10.1111/jnc.12672

119. Taniguchi $M$, Kitatani K, Kondo $T$, Hashimoto-Nishimura $M$, Asano S, Hayashi A, Mitsutake S, Igarashi Y, Umehara H, Takeya H, Kigawa J, and Okazaki $T$ (2012). Regulation of autophagy and its associated cell death by "sphingolipid rheostat": reciprocal role of ceramide and sphingosine 1-phosphate in the mammalian target of rapamycin pathway. J Biol Chem 287(47): 39898-39910. doi: 10.1074/jbc.M112.416552

120. Lee JK, Jin HK, Park MH, Kim B, Lee PH, Nakauchi H, Carter JE, He $X$, Schuchman EH, and Bae J (2014). Acid sphingomyelinase modulates the autophagic process by controlling lysosomal biogenesis in Alzheimer's disease. J Exp Med 211(8): 1551-1570. doi: 10.1084/jem.20132451

121. Justice MJ, Bronova I, Schweitzer KS, Poirier C, Blum JS, Berdyshev E V., and Petrache I (2018). Inhibition of acid sphingomyelinase disrupts LYNUS signaling and triggers autophagy. J Lipid Res 59(4): 596-606. doi: 10.1194/jlr.M080242

122. Matarrese $P$, Garofalo T, Manganelli V, Gambardella L, Marconi M, Grasso M, Tinari A, Misasi R, Malorni W, and Sorice M (2014). Evidence for the involvement of GD3 ganglioside in autophagosome formation and maturation. Autophagy 10(5): 750-765. doi: 10.4161/auto. 27959

123. Garofalo T, Matarrese $P$, Manganelli $V$, Marconi $M$, Tinari A, Gambardella L, Faggioni A, Misasi R, Sorice M, and Malorni W (2016) Evidence for the involvement of lipid rafts localized at the ERmitochondria associated membranes in autophagosome formation. Autophagy 12(6): 917-935. doi: 10.1080/15548627.2016.1160971 
124. Copetti T, Bertoli C, Dalla E, Demarchi F, and Schneider C (2009). p65/RelA Modulates BECN1 Transcription and Autophagy. Mol Cell Biol 29(10): 2594-2608. doi: 10.1128/mcb.01396-08

125. Boland MP, and O'Neill LA (1998). Ceramide activates NFkappaB by inducing the processing of p105. J Biol Chem 273(25): 1549415500. doi: $10.1074 / j b c .273 .25 .15494$

126. Demarchi F, Bertoli C, Greer PA, and Schneider C (2005). Ceramide triggers an NF-kappaB-dependent survival pathway through calpain. Cell Death Differ 12(5): 512-522. doi: 10.1038/sj.cdd.4401592

127. Pattingre S, Bauvy C, Carpentier S, Levade T, Levine $B$, and Codogno P (2009). Role of JNK1-dependent Bcl-2 phosphorylation in ceramide-induced macroautophagy. J Biol Chem 284(5): 2719-2728. doi: 10.1074/jbc.M805920200

128. Wu H, Wang MC, and Bohmann D (2009). JNK protects Drosophila from oxidative stress by trancriptionally activating autophagy. Mech Dev 126(8-9): 624-637. doi 10.1016/j.mod.2009.06.1082

129. Sun T, Li DD, Wang LL, Xia LP, Ma JG, Guan Z, Feng GK, and Zhu XF (2011). C-Jun NH2-terminal kinase activation is essential for upregulation of LC3 during ceramide-induced autophagy in human nasopharyngeal carcinoma cells. J Transl Med 9(1): 1-10. doi: 10.1186/1479-5876-9-161

130. Moruno Manchon JF, Uzor N-E, Dabaghian Y, Furr-Stimming EE, Finkbeiner S, and Tsvetkov AS (2015). Cytoplasmic sphingosine-1phosphate pathway modulates neuronal autophagy. Sci Rep 5: 15213. doi: 10.1038/srep15213

131. Yamamoto H, Kakuta $S$, Watanabe TM, Kitamura A, Sekito T, Kondo-Kakuta C, Ichikawa R, Kinjo M, and Ohsumi Y (2012). Atg9 vesicles are an important membrane source during early steps of autophagosome formation. J Cell Biol 198(2): 219-33. doi: 10.1083/jcb.201202061

132. Hinkovska-Galcheva V, Boxer LA, Kindzelskii A, Hiraoka M, Abe A, Goparju S, Spiegel S, Petty HR, and Shayman JA (2005). Ceramide 1phosphate, a mediator of phagocytosis. J Biol Chem 280(28): 2661226621. doi: 10.1074/jbc.M501359200

133. Mishra SK, Gao YG, Deng Y, Chalfant CE, Hinchcliffe EH, and Brown RE (2018). CPTP: A sphingolipid transfer protein that regulates autophagy and inflammasome activationt. Autophagy 14(5): 862-879. doi: 10.1080/15548627.2017.1393129

134. Corcelle-Termeau E, Vindeløv SD, Hämälistö S, Mograbi B Keldsbo A, Bräsen JH, Favaro E, Adam D, Szyniarowski P, Hofman P, Krautwald S, Farkas T, Petersen NHT, Rohde M, Linkermann A, and Jäättelä $M$ (2016). Excess sphingomyelin disturbs ATG9A trafficking and autophagosome closure. Autophagy 12(5): 833-849. doi: 10.1080/15548627.2016.1159378

135. Mitroi DN, Karunakaran I, Gräler M, Saba JD, Ehninger D, Ledesma MD, and van Echten-Deckert G (2017). SGPL1 (sphingosine phosphate lyase 1) modulates neuronal autophagy via phosphatidylethanolamine production. Autophagy 13(5): 885-899. doi: 10.1080/15548627.2017.1291471

136. Dany M, Gencer S, Nganga R, Thomas RJ, Oleinik N, Baron KD, Szulc ZM, Ruvolo P, Kornblau S, Andreeff M, and Ogretmen B (2016). Targeting FLT3-ITD signaling mediates ceramide-dependent mitophagy and attenuates drug resistance in AML. Blood 128(15): 1944-1958. doi: 10.1182/blood-2016-04-708750

137. Mizumura K, Justice MJ, Schweitzer KS, Krishnan S, Bronova I, Berdyshev E V., Hubbard WC, Pewzner-Jung Y, Futerman AH, Cho AMK, and Petrache I (2018). Sphingolipid regulation of lung epithelial cell mitophagy and necroptosis during cigarette smoke exposure. FASEB J 32(4): 1880-1890. doi: 10.1096/fj.201700571R
138. Sentelle RD, Senkal CE, Jiang W, Ponnusamy S, Gencer S, Selvam SP, Ramshesh VK, Peterson YK, Lemasters JJ, Szulc ZM, Bielawski J, Ogretmen B (2016). Ceramide targets autophagosomes to mitochondria and induces lethal mitophagy. Nat Chem Biol 118(24): 6072-6078. doi: 10.1038/nchembio.1059

139. Slattum G, Gu Y, Sabbadini R, and Rosenblatt J (2014). Autophagy in oncogenic K-Ras promotes basal extrusion of epithelial cells by degrading S1P. Curr Biol 24(1): 19-28. doi: 10.1016/j.cub.2013.11.029

140. Nixon $R$ a (2013). The role of autophagy in neurodegenerative disease. Nat Med 19(8): 983-97. doi: 10.1038/nm.3232

141. Hara T, Nakamura K, Matsui M, Yamamoto A, Nakahara Y, SuzukiMigishima R, Yokoyama M, Mishima K, Saito I, Okano H, and Mizushima N (2006). Suppression of basal autophagy in neural cells causes neurodegenerative disease in mice. Nature 441(7095): 885889. doi: $10.1038 /$ nature04724

142. Juhász G, Erdi B, Sass M, and Neufeld TP (2007). Atg7-dependent autophagy promotes neuronal health, stress tolerance, and longevity but is dispensable for metamorphosis in Drosophila. Genes Dev 21(23): 3061-6. doi: 10.1101/gad.1600707

143. Chen D, Zhu C, Wang X, Feng X, Pang S, Huang W, Hawley RG, and Yan B (2013). A novel and functional variant within the ATG5 gene promoter in sporadic Parkinson's disease. Neurosci Lett 538: 49-53. doi: 10.1016/j.neulet.2013.01.044

144. Chen D, Pang S, Feng X, Huang W, Hawley RG, and Yan B (2013) Genetic analysis of the ATG7 gene promoter in sporadic Parkinson's disease. Neurosci Lett 534: 193-8. doi: 10.1016/j.neulet.2012.12.039

145. Yamamoto A, Lucas JJ, and Hen R (2000). Reversal of Neuropathology and Motor Dysfunction in a Conditional Model of Huntington's Disease. Cell 101(1): 57-66. doi: 10.1016/S0092 8674(00)80623-6

146. Komatsu M, Waguri S, Koike M, Sou $Y$-S, Ueno $T$, Hara $T$ Mizushima N, Iwata J-I, Ezaki J, Murata S, Hamazaki J, Nishito $Y$ lemura S-I, Natsume T, Yanagawa T, Uwayama J, Warabi E, Yoshida $\mathrm{H}$ Ishii T, Kobayashi A, Yamamoto M, Yue Z, Uchiyama Y, Kominami E, and Tanaka K (2007). Homeostatic levels of p62 control cytoplasmic inclusion body formation in autophagy-deficient mice. Cell 131(6): 1149-1163. doi: 10.1016/j.cell.2007.10.035

147. Zhou J, Wang J, Cheng Y, Chi Y-J, Fan B, Yu J-Q, and Chen Z (2013). NBR1-mediated selective autophagy targets insoluble ubiquitinated protein aggregates in plant stress responses. PLoS Genet 9(1): e1003196. doi: 10.1371/journal.pgen.1003196

148. Korac J, Schaeffer V, Kovacevic I, Clement AM, Jungblut B, Behl C Terzic J, and Dikic I (2013). Ubiquitin-independent function of optineurin in autophagic clearance of protein aggregates. J Cell Sci 126(Pt 2): 580-592. doi: 10.1242/jcs.114926

149. Novak I, Kirkin V, McEwan DG, Zhang J, Wild P, Rozenknop A Rogov V, Lohr F, Popovic D, Occhipinti A, Reichert AS, Terzic J, Dotsch V, Ney PA, and Dikic I (2010). Nix is a selective autophagy receptor for mitochondrial clearance. EMBO Rep 11(1): 45-51. doi: 10.1038/embor.2009.256

150. Ravikumar B, Vacher C, Berger Z, Davies JE, Luo S, Oroz LG Scaravilli F, Easton DF, Duden R, O'Kane CJ, and Rubinsztein DC (2004). Inhibition of mTOR induces autophagy and reduces toxicity of polyglutamine expansions in fly and mouse models of Huntington disease. Nat Genet 36(6):585-95. doi: 10.1038/ng1362.

151. Ravikumar B, Berger Z, Vacher C, O'Kane CJ, and Rubinsztein DC (2006). Rapamycin pre-treatment protects against apoptosis. Hum Mol Genet 15(7): 1209-1216. doi: 10.1093/hmg/ddl036

152. Ravikumar B, Duden R, and Rubinsztein DC (2002). Aggregateprone proteins with polyglutamine and polyalanine expansions are degraded by autophagy. Hum Mol Genet 11: 1107-1117. doi: 


\subsection{3/hmg/11.9.1107}

153. Webb JL, Ravikumar B, Atkins J, Skepper JN, and Rubinsztein DC (2003). $\alpha$-synuclein Is Degraded by Both Autophagy and the Proteasome. J Biol Chem 278(27):25009-13. doi: 10.1074/jbc.M300227200

154. Kabuta T, Suzuki $Y$, and Wada K (2006). Degradation of amyotrophic lateral sclerosis-linked mutant $\mathrm{Cu}, \mathrm{Zn}$-superoxide dismutase proteins by macroautophagy and the proteasome. J Biol Chem 281(41): 30524-30533. doi: 10.1074/jbc.M603337200

155. Friedman LG, Lachenmayer ML, Wang J, He L, Poulose SM, Komatsu M, Holstein GR, and Yue Z (2012). Disrupted Autophagy Leads to Dopaminergic Axon and Dendrite Degeneration and Promotes Presynaptic Accumulation of -Synuclein and LRRK2 in the Brain. J Neurosci 32(22):7585-93. doi: 10.1523/jneurosci.580911.2012

156. Cuervo AM, Stafanis L, Fredenburg R, Lansbury PT, and Sulzer D (2004). Impaired degradation of mutant $\alpha$-synuclein by chaperonemediated autophagy. Science 305(5688):1292-5. doi: 10.1126/science. 1101738

157. Ravikumar B (2002). Aggregate-prone proteins with polyglutamine and polyalanine expansions are degraded by autophagy Hum Mol Genet 11(9):1107-17. doi: 10.1093/hmg/11.9.1107

158. Chow CY, Zhang Y, Dowling JJ, Jin N, Adamska M, Shiga K, Szigeti K, Shy ME, Li J, Zhang X, Lupski JR, Weisman LS, and Meisler MH (2007). Mutation of FIG4 causes neurodegeneration in the pale tremor mouse and patients with CMT4J. Nature 448(7149): 68-72. doi: $10.1038 /$ nature05876

159. Zhang Y, Zolov SN, Chow CY, Slutsky SG, Richardson SC, Piper RC Yang B, Nau JJ, Westrick RJ, Morrison SJ, Meisler MH, and Weisman LS (2007). Loss of Vac14, a regulator of the signaling lipid phosphatidylinositol 3,5-bisphosphate, results in neurodegeneration in mice. Proc Natl Acad Sci U S A 104(44): 17518-17523. doi: 10.1073/pnas.0702275104

160. Ferguson CJ, Lenk GM, and Meisler MH (2009). Defective autophagy in neurons and astrocytes from mice deficient in $\mathrm{PI}(3,5) \mathrm{P} 2$. Hum Mol Genet 18(24): 4868-4878. doi: 10.1093/hmg/ddp460

161. Bharadwaj R, Cunningham KM, Zhang K, and Lloyd TE (2016). FIG4 regulates lysosome membrane homeostasis independent of phosphatase function. Hum Mol Genet 25(4): 681-692. doi: 10.1093/hmg/ddv505

162. Al-Ramahi I, Giridharan SSP, Chen Y-C, Patnaik S, Safren N Hasegawa J, de Haro M, Wagner Gee AK, Titus SA, Jeong H, Clarke J, Krainc $D$, Zheng $W$, Irvine RF, Barmada S, Ferrer $M$, Southall $N$, Weisman LS, Botas J, and Marugan JJ (2017). Inhibition of PIP4Kgamma ameliorates the pathological effects of mutant huntingtin protein. Elife 6: e29123. doi: 10.7554/eLife.29123

163. Kegel KB, Kim M, Sapp E, McIntyre C, Castano JG, Aronin N, and DiFiglia $M$ (2000). Huntingtin expression stimulates endosomallysosomal activity, endosome tubulation, and autophagy. J Neurosci 20(19): 7268-7278. doi: 10.1523/jneurosci.20-19-07268.2000

164. Kegel KB, Sapp E, Alexander J, Valencia A, Reeves P, Li X, Masso N Sobin L, Aronin N, and DiFiglia M (2009). Polyglutamine expansion in huntingtin alters its interaction with phospholipids. J Neurochem 110(5): 1585-1597. doi: 10.1111/j.1471-4159.2009.06255.x

165. Lobasso S, Tanzarella P, Vergara D, Maffia M, Cocco T, and Corcelli A (2017). Lipid profiling of parkin-mutant human skin fibroblasts. J Cell Physiol 232(12): 3540-3551. doi: 10.1002/jcp.25815

166. Gaudioso A, Garcia-Rozas P, Casarejos MJ, Pastor O, and Rodriguez-Navarro JA (2019). Lipidomic Alterations in the Mitochondria of Aged Parkin Null Mice Relevant to Autophagy. Front Neurosci 13: 329. doi: 10.3389/fnins.2019.00329
167. Murdoch JD, Rostosky CM, Gowrisankaran S, Arora AS, Soukup SF, Vidal R, Capece V, Freytag S, Fischer A, Verstreken P, Bonn S, Raimundo N, and Milosevic I (2016). Endophilin-A Deficiency Induces the Foxo3a-Fbxo32 Network in the Brain and Causes Dysregulation of Autophagy and the Ubiquitin-Proteasome System. Cell Rep 17(4): 1071-1086. doi: 10.1016/j.celrep.2016.09.058

168. Chang D, Nalls MA, Hallgrímsdóttir IB, Hunkapiller J, van der Brug M, Cai F, Kerchner GA, Ayalon G, Bingol B, Sheng M, Hinds D, Behrens TW, Singleton $A B$, Bhangale TR, and Graham RR (2017). A metaanalysis of genome-wide association studies identifies 17 new Parkinson's disease risk loci. Nat Genet 49(10): 1511-1516. doi: 10.1038/ng.3955

169. Zhu L, Zhong M, Elder GA, Sano M, Holtzman DM, Gandy S, Cardozo C, Haroutunian V, Robakis NK, and Cai D (2015). Phospholipid dysregulation contributes to ApoE4-associated cognitive deficits in Alzheimer's disease pathogenesis. Proc Natl Acad Sci U S A 112(38): 11965-11970. doi: 10.1073/pnas.1510011112

170. He Y, Wei M, Wu Y, Qin H, Li W, Ma X, Cheng J, Ren J, Shen Y, Chen $Z$, Sun $B$, Huang $F$ De, Shen $Y$, and Zhou YD (2019). Amyloid $\beta$ oligomers suppress excitatory transmitter release via presynaptic depletion of phosphatidylinositol-4,5-bisphosphate. Nat Commun 10(1):1193. doi: 10.1038/s41467-019-09114-z

171. Han X, M Holtzman D, McKeel DWJ, Kelley J, and Morris JC (2002). Substantial sulfatide deficiency and ceramide elevation in very early Alzheimer's disease: potential role in disease pathogenesis. J Neurochem 82(4): 809-818. doi: 10.1046/j.1471-4159.2002.00997.x

172. Lambert J-C et al. (2011). Evidence of the association of BIN1 and PICALM with the $A D$ risk in contrasting European populations. Neurobiol Aging 32(4): 756.e11-5. doi: 10.1016/j.neurobiolaging.2010.11.022

173. Tian Y, Chang JC, Fan EY, Flajolet $M$, and Greengard P (2013). Adaptor complex AP2/PICALM, through interaction with LC3, targets Alzheimer's APP-CTF for terminal degradation via autophagy. Proc Natl Acad Sci U S A 110(42): 17071-17076. doi: 10.1073/pnas.1315110110

174. Campuzano V, Montermini L, Molto MD, Pianese L, Cossee $M$ Cavalcanti F, Monros E, Rodius F, Duclos F, Monticelli A, Zara F, Canizares J, Koutnikova H, Bidichandani SI, Gellera C, Brice A, Trouillas P, De Michele G, Filla A, De Frutos R, Palau F, Patel PI, Di Donato S, Mandel JL, Cocozza S, Koenig M, and Pandolfo M (1996). Friedreich's ataxia: autosomal recessive disease caused by an intronic GAA triplet repeat expansion. Science 271(5254): 1423-1427. doi 10.1126/science. 271.5254 .1423

175. Campuzano V, Montermini L, Lutz Y, Cova L, Hindelang C, Jiralerspong S, Trottier $\mathrm{Y}$, Kish SJ, Faucheux B, Trouillas $\mathrm{P}$, Authier FJ, Durr A, Mandel JL, Vescovi A, Pandolfo M, and Koenig M (1997). Frataxin is reduced in Friedreich ataxia patients and is associated with mitochondrial membranes. Hum Mol Genet 6(11): 1771-1780. doi: 10.1093/hmg/6.11.1771

176. Ross BM, Eder K, Moszczynska A, Mamalias N, Lamarche J, Ang L, Pandolfo M, Rouleau G, Kirchgessner M, and Kish SJ (2000). Abnormal activity of membrane phospholipid synthetic enzymes in the brain of patients with Friedreich's ataxia and spinocerebellar atrophy type-1. Mov Disord 15(2): 294-300. doi: 10.1002/15318257(200003)15:2<294::aid-mds1013>3.0.co;2-d

177. Bayot A, Reichman S, Lebon S, Csaba Z, Aubry L, Sterkers G, Husson I, Rak M, and Rustin P (2013). Cis-silencing of PIP5K1B evidenced in Friedreich's ataxia patient cells results in cytoskeleton anomalies. Hum Mol Genet 22(14): 2894-2904. doi: 10.1093/hmg/ddt144

178. Simon D, Seznec $H$, Gansmuller A, Carelle N, Weber P, Metzger D, Rustin $P$, Koenig $M$, and Puccio $H$ (2004). Friedreich ataxia mouse models with progressive cerebellar and sensory ataxia reveal 
autophagic neurodegeneration in dorsal root ganglia. J Neurosci 24(8): 1987-1995. doi: 10.1523/JNEUROSCI.4549-03.2004

179. Farfel-Becker T, Vitner EB, Kelly SL, Bame JR, Duan J, Shinder V, Merrill AHJ, Dobrenis $K$, and Futerman $A H$ (2014). Neuronal accumulation of glucosylceramide in a mouse model of neuronopathic Gaucher disease leads to neurodegeneration. Hum Mol Genet 23(4): 843-854. doi: $10.1093 / \mathrm{hmg} / \mathrm{ddt} 468$

180. Fuller $M$, and Futerman $A H$ (2018). The brain lipidome in neurodegenerative lysosomal storage disorders. Biochem Biophys Res Commun 504(3): 623-628. doi: 10.1016/j.bbrc.2018.03.042

181. Spassieva SD, Ji X, Liu Y, Gable K, Bielawski J, Dunn TM, Bieberich $E$, and Zhao $L$ (2016). Ectopic expression of ceramide synthase 2 in neurons suppresses neurodegeneration induced by ceramide synthase 1 deficiency. Proc Natl Acad Sci U S A 113(21): 5928-5933. doi: $10.1073 /$ pnas.1522071113

182. Lieberman AP, Puertollano R, Raben N, Slaugenhaupt S, Walkley $\mathrm{SU}$, and Ballabio A (2012). Autophagy in lysosomal storage disorders. Autophagy 8(5): 719-730. doi: 10.4161/auto.19469

183. Ariga T, Jarvis WD, and Yu RK (1998). Role of sphingolipidmediated cell death in neurodegenerative diseases. J Lipid Res 39(1): 1-16. PMID: 9469581

184. Suzuki K, Katzman R, and Korey SR (1965). Chemical Studies on Alzheimer's Disease. J Neuropathol Exp Neurol 24(2): 211-224. doi: 10.1097/00005072-196504000-00004

185. Brugg B, Michel PP, Agid Y, and Ruberg M (1996). Ceramide induces apoptosis in cultured mesencephalic neurons. J Neurochem 66(2): 733-739. doi: 10.1046/j.1471-4159.1996.66020733.x

186. Cuvillier O, Pirianov G, Kleuser B, Vanek PG, Coso OA, Gutkind S, and Spiegel $S$ (1996). Suppression of ceramide-mediated programmed cell death by sphingosine-1-phosphate. Nature 381(6585): 800-803. doi: $10.1038 / 381800 \mathrm{aO}$

187. Edsall LC, Pirianov GG, and Spiegel S (1997). Involvement of sphingosine 1-phosphate in nerve growth factor-mediated neuronal survival and differentiation. J Neurosci 17(18): 6952-6960. doi: 10.1523/jneurosci.17-18-06952.1997

188. Moruno-Manchon JF, Uzor NE, Ambati CR, Shetty V, Putluri N, Jagannath C, McCullough LD, and Tsvetkov AS (2018). Sphingosine kinase 1-associated autophagy differs between neurons and astrocytes. Cell Death Dis 9(5): 521. doi: 10.1038/s41419-018-0599-5

189. Katsel P, Li C, and Haroutunian V (2007). Gene expression alterations in the sphingolipid metabolism pathways during progression of dementia and Alzheimer's disease: a shift toward ceramide accumulation at the earliest recognizable stages of Alzheimer's disease? Neurochem Res 32(4-5): 845-856. doi: 10.1007/s11064-007-9297-x
190. He X, Huang Y, Li B, Gong C-X, and Schuchman EH (2010). Deregulation of sphingolipid metabolism in Alzheimer's disease. Neurobiol Aging 31(3): 398-408. doi: 10.1016/j.neurobiolaging.2008.05.010

191. Lee JK, Jin HK, Park MH, Kim BR, Lee PH, Nakauchi H, Carter JE, $\mathrm{He} X$, Schuchman EH, and Bae JS (2014). Acid sphingomyelinase modulates the autophagic process by controlling lysosomal biogenesis in Alzheimer's disease. J Exp Med 211(8): 1551-1570. doi: 10.1084/jem.20132451

192. Mazzulli JR, Xu Y-H, Sun Y, Knight AL, McLean PJ, Caldwell GA, Sidransky E, Grabowski GA, and Krainc D (2011). Gaucher disease glucocerebrosidase and alpha-synuclein form a bidirectional pathogenic loop in synucleinopathies. Cell 146(1): 37-52. doi: 10.1016/j.cell.2011.06.001

193. Sidransky E et al. (2009). Multicenter analysis of glucocerebrosidase mutations in Parkinson's disease. N Engl J Med 361(17): 1651-1661. doi: 10.1056/NEJMoa0901281

194. Lin G, Wang L, Marcogliese PC, and Bellen HJ (2019). Sphingolipids in the Pathogenesis of Parkinson's Disease and Parkinsonism. Trends Endocrinol Metab 30(2): 106-117. doi: 10.1016/j.tem.2018.11.003

195. van Echten-Deckert G, and Alam S (2018). Sphingolipid metabolism - an ambiguous regulator of autophagy in the brain. Biol Chem 399(8): 837-850. doi: 10.1515/hsz-2018-0237

196. Ledesma MD, Martin MG, and Dotti CG (2012). Lipid changes in the aged brain: effect on synaptic function and neuronal survival. Prog Lipid Res 51(1): 23-35. doi: 10.1016/j.plipres.2011.11.004

197. Cheng J, Fujita A, Yamamoto H, Tatematsu T, Kakuta S, Obara K, Ohsumi $Y$, and Fujimoto $T$ (2014). Yeast and mammalian autophagosomes exhibit distinct phosphatidylinositol 3-phosphate asymmetries. Nat Commun 5: 3207. doi: 10.1038/ncomms4207

198. Luo X, Zhao X, Cheng C, Li N, Liu Y, and Cao Y (2018). The implications of signaling lipids in cancer metastasis. Exp Mol Med 50(9): 127. doi: 10.1038/s12276-018-0150-x

199. Shaw J, Costa-Pinheiro P, Patterson L, Drews K, Spiegel S, and Kester M (2018). Novel Sphingolipid-Based Cancer Therapeutics in the Personalized Medicine Era. Adv Cancer Res 140: 327-366. doi: 10.1016/bs.acr.2018.04.016

200. Giles LM, Li L, and Chin L-S (2009). TorsinA protein degradation and autophagy in DYT1 dystonia. Autophagy 5(1): 82-84. doi: 10.4161/auto.5.1.7173

201. Grillet M, Dominguez Gonzalez B, Sicart A, Pottler M, Cascalho A, Billion K, Hernandez Diaz S, Swerts J, Naismith T V, Gounko N V, Verstreken P, Hanson PI, and Goodchild RE (2016). Torsins Are Essential Regulators of Cellular Lipid Metabolism. Dev Cell 38(3): 235247. doi: 10.1016/j.devcel.2016.06.017 